\title{
Learning and Bargaining in Dispute Resolution: Theory and Evidence from Medical Malpractice Litigation
}

\author{
Yasutora Watanabe* \\ University of Pennsylvania \\ (JOB MARKET PAPER)
}

November, 2004

\begin{abstract}
Lengthy legal procedures and high legal costs are among the main drawbacks of the current litigation system in the United States. This paper studies the dispute resolution process with special emphasis on the dynamic patterns of litigation and settlement as well as the legal costs incurred and associated payments. I propose a dynamic bargaining model of dispute resolution with learning, estimate the model using micro data on medical malpractice disputes, and use the estimated model to assess the impact of proposed tort reforms. In my model the plaintiff and the defendant do not have a common prior on the probability of winning court judgment and learning takes place as they bargain. In the equilibrium, a trade-off between the legal costs of delaying agreement and the possibility of learning new information determines the dynamic patterns of litigation and settlement. Estimation results show that the model fits all aspects of the data well and learning plays a quantitatively important role in explaining the dynamic patterns of litigation and settlement. Using the estimated model, I conduct policy experiments to assess some of the proposed tort reforms. I find that capping jury awards or eliminating the contingency fee rule significantly shortens the expected time to resolution and lowers the expected total legal costs. Since shorter legal procedures would reduce congestion in the legal system and savings of legal costs would lower the deadweight loss of litigation, I conclude that these reforms could have important welfare implications. On the other hand, "loser-pay-all" allocation of legal fees delay resolution and increase costs.
\end{abstract}

${ }^{*}$ I am grateful to Antonio Merlo for invaluable guidance and encouragement and to Ken Wolpin for very helpful discussions and suggestions. I also benefitted from conversations with Hulya Eraslan, Elena Krasnokutskaya, George Mailath, Sankar Mukhopadhyay, Elena Pastorino, and Chris Sanchirico. I thank Gilbert Gimm for helpful information on the data set.

${ }^{\dagger}$ Department of Economics, University of Pennsylvania, 3718 Locust Walk, Philadelphia, PA $19104 . \quad$ Email: yasutora@econ.upenn.edu 


\section{Introduction}

In recent years, medical malpractice litigation has been at the forefront of the public policy debate in the United States. The annual cost of payments to medical malpractice claims, which includes both legal fees and compensation payments, was about $\$ 24$ billion in 2002 and has doubled in the past 12 years (Tillinghast Towers-Perrin, 2003). A commonly held opinion is that the high cost of medical malpractice litigation has contributed to rising health care costs (see e.g. U.S. Congress Joint Economic Committee, 2003). ${ }^{1}$

Lengthy legal procedures and high legal costs are among the main drawbacks of the current litigation system. ${ }^{2}$ In response to these problems, medical liability reforms, such as caps on jury awards or restrictions on lawyer fees, were adopted in many states during the 1990s and are currently under consideration at the federal level. ${ }^{3}$

This paper studies the process through which medical malpractice disputes are resolved. Special emphasis is given to the timing and the terms of dispute resolutions and the legal costs incurred by the negotiating parties. I propose a dynamic bargaining model of dispute resolution with learning, estimate the model using micro data on medical malpractice litigation, and use the estimated model to assess the impact of proposed tort reforms.

In the United States, doctors are liable for the damages caused by negligent care. Upon the alleged occurrence of such damage, the patient's claim against the doctor initiates a medical malpractice dispute. In this legal procedure, the plaintiff (i.e., the patient) and the defendant (i.e., the doctor) engage in negotiations over the terms of settlement in the shadow of court judgment. If the plaintiff files a lawsuit and the parties do not reach an agreement, they will face a judgment by the court, which determines whether the defendant is liable and, if so, the award to the plaintiff.

To study this process, I propose a dynamic model in which, following the occurrence of an alleged instance of medical malpractice, the plaintiff and the defendant bargain over a settlement. At any time during the negotiation, as long as no agreement has been reached, the plaintiff has

\footnotetext{
${ }^{1}$ Medical malpractice litigation may also affect health care costs indirectly, through "defensive medicine" aimed at preventing litigation. Although this paper focuses on the direct cost of litigation, I discuss the issue of "defensive medicine" in Section 6 below.

${ }^{2}$ For example, Senator Joseph Leiberman argues in his speech during a Senate debate on March 21, 1996 (quoted by Babcock and Pogarsky, 1999)

"Everybody in America knows, at least most everybody know, that our Civil Justice System is not working well. We do not think anybody really can stand up and defend the status quo of the litigation system in America. The average person on the street - we stop them in Hartford, New Haven, Bridgeport - knows that lawsuits take too long; that people do not get justice in a timely fashion; that too much money goes to lawyers."

${ }^{3}$ In the U.S., medical malpractice liability is governed by state law. However, the Commerce Clause of the Constitution allows regulation by federal law. The House of Representatives passed the Help Efficient, Accessible, Low-Cost, Timely Healthcare (HEALTH) Act of 2003 in the 108th Congress, while the Senate voted against it. The bill has been reintroduced in 2004 and is currently under consideration.
} 
the option of filing a lawsuit that would initiate the litigation phase. If no agreement is reached during the litigation phase, the case is resolved in court, where a jury verdict determines whether the defendant is liable and, if so the award to the plaintiff. In any period prior to the termination of a dispute, the defendant must pay a legal cost which I allow to differ depending on whether or not the plaintiff has filed a lawsuit. In particular, the defendant's legal costs are typically higher in the litigation phase, which entails additional legal procedures with respect to the pre-litigation phase. On the other hand, the plaintiff's legal costs are a fixed fraction of the compensation payment and are paid upon resolution of the dispute (the so-called "contingency fee rule").

I assume that the plaintiff and the defendant do not have a common prior over the probability of prevailing at trial. This asymmetry in initial beliefs may be due, for example, to differences in each party's perception of the relative ability of his or her lawyer, or to differences in opinion about the predisposition of potential juries. This assumption generates the possibility that parties may fail to reach an agreement over the terms of a settlement. As new information is revealed during bargaining, learning takes place and the negotiating parties update their expectations of obtaining a favorable verdict. I allow the rate of arrival of information to differ in the pre-litigation and the litigation phases, for example because of the "discovery process" which follows the filing of a lawsuit. Learning has the effect of drawing the plaintiff and defendant's expectations of the trial results closer to each other, which in turn increases the probability of agreement.

I characterize the unique subgame-perfect equilibrium of this dynamic bargaining game. Equilibrium outcomes specify the plaintiff's decision of whether to file a lawsuit and if so the time to filing, whether or not the case is settled out of court, the time to resolution, the legal costs incurred and the terms of settlement. Delaying agreement is costly because of the per-period lawyer fees. However, the possibility of learning new information makes delay valuable. This fundamental trade-off plays an important role in the equilibrium characterization and is a key determinant of the time to filing and the time to settlement. I find that the higher the rate at which new information arrives in bargaining, the shorter the time to settlement and the lower the legal costs. Furthermore, higher expected jury awards and more optimistic initial beliefs delay settlement.

I estimate the model using a unique data set on individual medical malpractice disputes. The data set contains detailed information on the time, mode, cost, and terms of settlement as well as the time of filing lawsuit (if a lawsuit is filed) for all medical malpractice disputes in Florida over the period 1985-1999. The model fits all aspects of the data well. I find that learning plays a quantitatively important role in explaining the dynamic patterns of litigation and settlement observed in the data.

I use the estimated structural model to conduct policy experiments and evaluate the effects of proposed reforms of the medical liability system. I find that capping jury awards or eliminating the contingency fee rule significantly shortens the expected time to resolution and lowers the expected total legal costs. Since shorter legal procedures would reduce congestion in the legal system and 
savings of legal costs would lower the deadweight loss of litigation, I conclude that these reforms could have important welfare implications. On the other hand, replacing the current system with the "loser-pay-all" allocation of legal fees would not be a desirable policy, since it would delay resolution and increase costs.

There is a large theoretical literature on bargaining models of dispute resolution (see, e.g., the survey by Cooter and Rubinfeld, 1989). A significant fraction of the literature considers models similar to the one I propose in this paper, in which the negotiating parties do not have a common prior belief over the probability of prevailing at trial (e.g., Landes, 1971; Posner, 1973; Priest and Klein, 1984; and Wittman 1988). ${ }^{4}$ The main focus of these studies, however, is to analyze the parties' decision of whether or not to settle their dispute out of court. For this reason, existing contributions only consider two-period bargaining models in which failure to reach an agreement in the first period would lead to a jury verdict in the second period. As indicated above, one of the main goals of my paper is to study the timing of filing and settlement decisions in legal disputes. I therefore consider a dynamic bargaining model. ${ }^{5}$

As illustrated by Yildiz (2003) in the context of a "divide-the-dollar" game, simple extensions of bargaining models without a common prior to an n-period environment may not be able to explain the occurrence of delay. Within the context of bargaining models of dispute resolution, this implies that either the parties would settle immediately, or the case would be resolved by court judgement. By introducing learning in a dynamic bargaining model without a common prior, I show that delayed settlement can occur in equilibrium. ${ }^{6}$ Also, by making the plaintiff's decision to file lawsuit endogenous, I show that delays in filing can emerge in equilibrium.

Corresponding to the theoretical literature summarized above, the main focus of the empirical literature on dispute resolution to date has been the estimation of the probability of defendants prevailing at trial and/or the probability of cases settling out of court. ${ }^{7}$ The two papers that are most closely related to mine are Waldfogel (1995) and Sieg (2000). Waldfogel (1995) uses data on the mode of resolution of civil disputes to estimate a two-period bargaining model with without a common prior. Using the same data set I use in this paper, Sieg (2000) estimates a two-period

\footnotetext{
${ }^{4}$ Another strand of the literature considers instead bargaining models with asymmetric information (see, e.g., Bebchuk, 1984; Nalebuff, 1987; Reinganum and Wilde, 1986; Spier 1992).

${ }^{5}$ Bebchuk (1996) considers an n-period barganinig model to explain why a plaintiff may file a lawsuit even though the expected value of litigation is negative. In his model, however, the players have identical expectations over the probability of prevailing at trial, and settlement always occurs in the initial period. Spier (1992) considers a dynamic bargaining model with asymmetric information, where in equilibrium the plaintiff makes a sequence of "screening" offers that only certain types of defendants accept, thus leading to the possibility of delay. Her analysis, however, abstracts from the plaintiff's decisions of whether and when to file a lawsuit.

${ }^{6}$ Cooter and Rubinfeld (1994) introduce an interim stage of "discovery" in a two-period model without a common prior to study the effect of the discovery process. They show that it is possible for a case to settle in the discovery stage. However, their paper abstracts from the decision of filing and is not interested in explaining the dynamic patterns of settlement and filing.

${ }^{7}$ See, e.g., the survey by Kessler and Rubinfeld (2004)
} 
bargaining model with asymmetric information to study the mode, cost, and terms of settlement in medical malpractice disputes. Neither paper, however, studies the dynamic patterns of filing and settlement in dispute resolution. ${ }^{8}$

My paper is also related to the empirical literature on tort reform. Yoon (2001) studies the effect of a reform implemented in Alabama that imposed a cap on jury awards. He finds that such a reform significantly reduced compensation payments. Using laboratory experiments, Babcock and Pogarsky (1999) find that caps on jury awards encourage settlement. Snyder and Hughes (1990) and Hughes and Snyder (1995) study the effect of a temporary implementation of the "loser-pay-all" rule for the allocation of legal fees in Florida and find that such rule increases settlement payments. The findings of my analysis are consistent with these results.

The remainder of the paper is organized as follows. In Section 2, I present the model and characterize the equilibrium. Section 3 describes the data and Section 4 presents the econometric specification. Section 5 contains the results of the empirical analysis. Policy experiments are presented in Section 6 and concluding remarks in Section 7.

\section{Model}

I consider a perfect-information sequential bargaining model of legal dispute resolution with stochastic learning. The players of the bargaining game are a plaintiff $(p)$ and a defendant $(d)$. The plaintiff and the defendant bargain over the compensation payment $x \in \mathcal{R}^{+}$from the defendant to the plaintiff to resolve the dispute. Each player $i \in\{d, p\}$ has linear von-Neumann-Morgenstern preferences over monetary transfer and legal costs. Both players know the amount of the potential jury award $V \in \mathcal{R}^{+}$, but the outcome of the judgement is uncertain, i.e. the players do not know who will win the case in the even of a trial. ${ }^{9}$ The defendant pays $V$ to the plaintiff if the plaintiff wins the judgment, while the defendant does not pay any amount otherwise. I denote the plaintiff's probability of prevailing by $\pi$.

Timing and Phases The bargaining game has two multi-period phases depending on whether the plaintiff has filed a lawsuit or not: the pre-litigation phase (Phase $O$ ) and the litigation phase (Phase $L$ ). The game starts with Phase $O$ at period $t=0$. Players bargain every period until

\footnotetext{
${ }^{8}$ There is a small empirical literature that uses duration analysis to estimate hazard models of dispute resolution. Kessler (1996), for example, estimates a duration model to assess the effect of institutional features of the legal system on the time to resolution of civil disputes (see, also Fournier and Zuehlke, 1996 and Fenn and Rickman, 1999). These studies, however, are not interested in explaining the time to filing, the terms of settlement, or the legal costs incurred by the negotiating parties.

${ }^{9}$ In the literature the uncertainty of the judgment is caused either 1) by the uncertainty of the winning party (see e.g., Pries and Klein(1984)) or 2) by the uncertainty of the award amount (see e.g. Spier (1992)). We take the former assumption because we can better explain the data in which large proportion of cases concludes with no monetary transfers at the court judgement.
} 


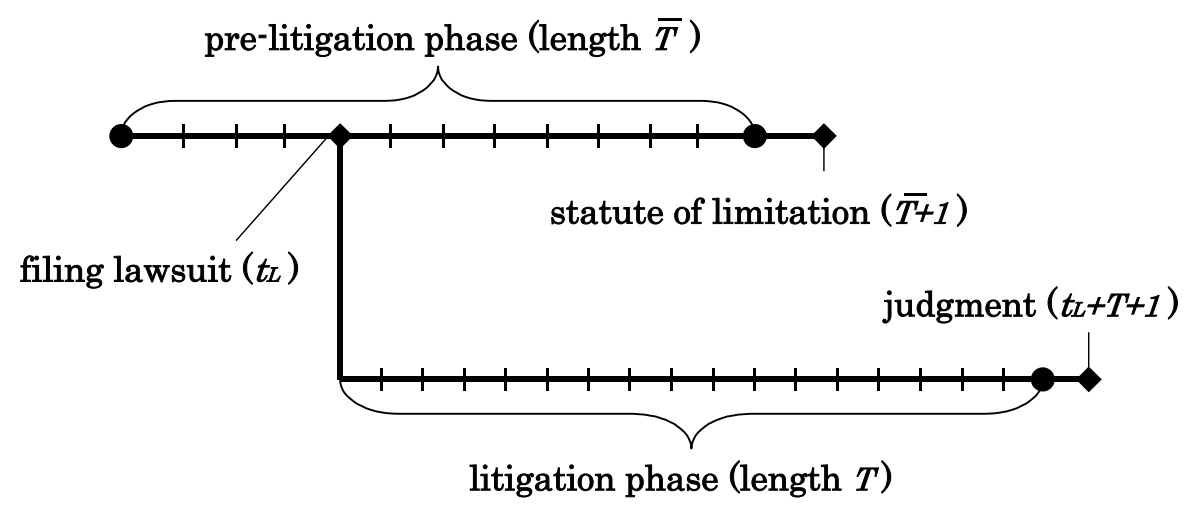

The plaintiff and the defendant start bargaining over a settlement in pre-litigation stage. At any time in pre-litigatioin stage, as long as no agreement has been reached, the plaintiff has the option of filing a lawsuit that endogenously determine $t_{L}$ and would initiate the litigation stage. If neither a lawsuit is filed nor a settlement is reached by $\bar{T}$ in pre-litigation phase, the case is no longer valid due to statute of limitation. If no agreement is reached during the litigation stage, the case is resolved by court judgment at $t_{L}+T+1$.

Figure 1: Diagram of Model Structure

they reach an agreement. Phase $O$ has a finite number of periods $\bar{T}<\infty$, due to the statute of limitation at period $t=\bar{T}+1<\infty$, after which the plaintiff's claim to recover is barred by law. The plaintiff has an option of filing a lawsuit in Phase $O$ as long as no agreement has been reached. The filing of a lawsuit moves the game to Phase $L$. Thus, a case may be filed (move to Phase $L$ ) or conclude in Phase $O$ either by a settlement (without filing a lawsuit) or by the statute of limitation.

The plaintiff's endogenous decision to file a lawsuit initiates Phase $L$. Let $t_{L} \in\{0, \ldots, \bar{T}\}$ denote the date of the filing of lawsuit. Once the plaintiff files a lawsuit, the case is processed in court towards the judgment scheduled $T+1$ periods after the date of filing, that is date $t=t_{L}+T+1<\infty$ . While the case is processed in court, the players can always agree to settle the case until $t=t_{L}+T$. Failure to reach a settlement agreement by $t=t_{L}+T$ results in the resolution by the court judgment at $t=t_{L}+T+1$.

Stage Games In Phase $O$, players play the following stage game in every period $t \in\{0, \ldots, \bar{T}\}$. At the beginning of each period, information arrives with probability $\lambda_{O t}$ and does not arrive with probability $1-\lambda_{O t}$. The information is such that it affects the outcome of the judgment (e.g., the result of third-party medical examination) and is commonly observed by both players. Then, 
nature chooses the proposer, with probability $\phi$ for the plaintiff and $1-\phi$ for the defendant. The chosen party proposes the amount of compensation payment $x$, which will be either accepted or rejected by the other party. If accepted, the game concludes with the proposed amount of money $x$ being transferred from the defendant to the plaintiff, and the dispute is resolved. If the proposal is rejected, the plaintiff chooses whether or not to file a lawsuit. The case moves to Phase $L$ if the plaintiff files a lawsuit, while it remains in Phase $O$ and the same stage game is repeated if the plaintiff chooses not to file. If the case is neither filed nor settled during the $\bar{T}$ periods, the statute of limitation renders the claim by the plaintiff to be ineffective.

After the filing of a lawsuit by the plaintiff, the parties play the following stage game in every period $t \in\left\{t_{L}, \ldots, t_{L}+T\right\}$ until the court judges on the case at $t=t_{L}+T+1$. At the beginning of each period, information that affects the outcome of the judgment arrives with probability $\lambda_{L t}$ and does not arrive with probability $1-\lambda_{L t}$. Then, nature again chooses the proposer, with probability $\phi$ for the plaintiff and $1-\phi$ for the defendant. The chosen party proposes the amount of compensation payment $x$, which will be either accepted or rejected by the other party. If accepted, the game terminates with the proposed amount of money being transferred from the defendant to the plaintiff, and the dispute is resolved. If rejected, the case remains in Phase $L$ and the same stage game is repeated until $t=t_{L}+T$.

I allow the rates of information arrival to differ across phases. One of the reasons is the "discovery process" in which both parties can employ a variety of legal devices to acquire information on the case that follows the filing of a lawsuit.

In civil disputes, including medical malpractice disputes, plaintiffs' lawyers use a contingency fee arrangement, while defendants' legal councils charge an hourly legal fee. The contingency fee arrangement makes the plaintiff's lawyers entitled to a fraction (typically one-third to 40\%) of the money received from the defendant only if a positive payment is received. This implies that the plaintiff bears no additional legal cost by delaying agreement, and that her objective is to maximize expected payment from the defendant. For the defendant, I assume per-period legal costs of $C_{O} \in R^{+}$and $C_{L} \in R^{+}$in Phases $O$ and $L$ respectively. I allow per-period costs to differ depending on whether or not the plaintiff has filed a lawsuit. In particular, the defendant's legal costs are typically higher in the litigation phase, which entails additional legal procedures with respect to the pre-litigation phase. I consider a common time-discount factor denoted by $\beta \in[0,1]$.

Information and Beliefs The model is a game of perfect information. As described above, the players can observe all the actions of the other player. The information revealed is also commonly observed by both players. Hence, there is no asymmetric information. The players, however, do not have a common prior over the probability that the plaintiff will win the case $(\pi)$. This asymmetry in initial beliefs may be due for example to differences in each party's perception of the relative ability of his or her lawyer or to differences in opinion about the predisposition of potential juries. 
I assume that the players' beliefs over the plaintiff's prevailing probability $\pi \in[0,1]$ have beta distributions, a flexible as well as tractable distribution with support $[0,1]$ that is widely used in statistical learning models on Bernoulli trial process. Player $i$ 's initial belief, denoted by $b_{0}^{i}$, are represented by $\operatorname{Beta}\left(\theta_{i}, \rho-\theta_{i}\right)$, where $0<\theta_{d}<\theta_{p}<\rho .{ }^{10}$ A common parameter $\rho$ represents the firmness of belief as explained later. Thus, at the initial date, the players have expected probability of plaintiff's prevailing as

$$
\begin{aligned}
& E\left(b_{0}^{p}\right)=\frac{\theta_{p}}{\rho} \text { for the plaintiff, and } \\
& E\left(b_{0}^{d}\right)=\frac{\theta_{d}}{\rho} \text { for the defendant. }
\end{aligned}
$$

At the beginning of each period $t$ in Phase $J \in\{O, L\}$, information related to winning probability (such as the result of a third party medical examination or testimony by an expert witness) arrives with probability $\lambda_{J}$. I denote an arrival of information at $t$ by $n^{t} \in\{0,1\}$, where $n^{t}=1$ means arrival of information while $n^{t}=0$ represents no arrival. The cumulated amount of information at period $t$ is denoted by $n_{t} \in\{0, \ldots, t\}$, and therefore

$$
n_{t}=n_{t-1}+n^{t}
$$

Information is either in favor of or against the plaintiff. I denote the content of the arrived information $n^{t}$ by $m^{t} \in\{0,1\}$. The content is for the plaintiff if $m^{t}=1$, while $m^{t}=0$ means the arrived information is against the plaintiff, and

$$
m^{t}=\left\{\begin{array}{l}
0 \quad \text { with probability } 1-\pi \\
1 \quad \text { with probability } \pi,
\end{array}\right.
$$

where $\pi$ is not known to the players. The cumulated information in favor of the plaintiff is denoted by $m_{t} \in\left\{0, \ldots, n_{t}\right\}$ and I have

$$
m_{t}=m_{t-1}+n^{t} m^{t}
$$

where $m^{t}$ is multiplied by $n^{t}$ since the content of information matters only if information arrives.

Players update their beliefs following Bayesian updating as follows: The beliefs at period $t$, denoted by $b_{t}^{p}$ and $b_{t}^{d}$, follow $\operatorname{Beta}\left(\theta_{p}+m_{t}, \rho-\theta_{p}+n_{t}-m_{t}\right)$ and $\operatorname{Beta}\left(\theta_{d}+m_{t}, \rho-\theta_{d}+n_{t}-m_{t}\right)$ respectively. Hence, at period $t$, the expectations on the probability $\pi$ of plaintiff's prevailing on the judgement are

$$
E\left(b_{t}^{p}\right)=\frac{\theta_{p}+m_{t}}{\rho+n_{t}}
$$

\footnotetext{
${ }^{10}$ See Yildiz (2004) for a similar setup. Arrival of information is deterministic in his model, while it is stochastic in my model.
} 
and

$$
E\left(b_{t}^{d}\right)=\frac{\theta_{d}+m_{t}}{\rho+n_{t}} .
$$

The players use these expectations as their estimates of $\pi$. The firmer the beliefs (i.e., the higher the firmness of belief parameter $\rho$ ), the less is the impact of the information obtained in the legal process. The information environment I have described above is common knowledge to both players.

For notational convenience, I let $k_{t}=\left(n_{t}, m_{t}\right) \in\{0, t\} \times\{0, t\}$ denote the information state.

\subsection{Equilibrium Characterization}

The model is a dynamic game with perfect information. Thus, I employ subgame-perfect equilibrium as the equilibrium concept. Because the model has a finite number of periods, backward induction provides us with a characterization of the unique subgame-perfect equilibrium. I start the analysis from the last stage in Phase $L$, and move to Phase $O$.

In order to clarify the role of learning in the model, I first characterize the equilibrium for the case in which there is no learning.

Proposition 1 If no learning takes place $\left(b_{t}^{i}=b^{i}\right.$ for any $t$ for $\left.i=p, d\right)$, the players either settle immediately or the case is resolved by court judgement. Players settle immediately iff

$$
\left(b^{p}-b^{d}\right) \beta^{T} V \leq \frac{\left(1+\beta^{T+1}\right) C_{L}}{(1-\beta)},
$$

and the case is resolved by the court judgment otherwise. The case is filed immediately if it is not settled immediately.

Proof. See Appendix A.

Proposition 1 states that delays in settlement and filing cannot occur if there is no learning. The parties settle immediately if their beliefs are sufficiently close, while they do not settle and the case is resolved by court judgment if their beliefs are far apart. The threshold condition can be interpreted intuitively. The left hand side of inequality (1) is the discounted difference in expected award and the right hand side represents the discounted sum of legal costs to be saved. If the total legal cost to be saved is large enough compared to the difference in expected award, the players settle immediately. The discounting is up to $t=T$ because the plaintiff will choose to file immediately if they do not settle immediately, since this award is discounted more if he files later. I consider the case with learning in the rest of the section. 


\subsubsection{Phase $L$ (Litigation Phase)}

I start my analysis from Phase $L$ following backward induction. Recall that a Phase $L$ subgame is reached only if the case is litigated at some period during Phase $O$. Let $t_{L} \in\{0, \ldots, \bar{T}\}$ denote the date of filing the lawsuit. If the players cannot settle by date $t_{L}+T$, the judgement by the court at $t=t_{L}+T+1$ determines the outcome of the last stage. Let $V_{t-t_{L}}^{i}\left(k_{t}\right)$ denote the continuation value for player $i \in\{p, d\}$ at the beginning of date $t$ in Phase $L$ with information state $k_{t}$. Note that the subscript is $t-t_{L}$, which is the number of periods in Phase $L$. I can write the continuation value of the judgment as

$$
V_{T+1}^{p}\left(k_{t_{L}+T+1}\right)=-V_{T+1}^{d}\left(k_{t_{L}+T+1}\right)=\left\{\begin{array}{cl}
V & \text { if the plaintiff prevails } \\
0 & \text { otherwise }
\end{array}\right.
$$

I obtain $V_{t-t_{L}}^{i}\left(k_{t}\right)$ by applying backward induction and having (2) as final values. To do so, I consider two separate cases depending on whether the players will settle or continue.

First, consider the case of $E_{t}^{p}\left[V_{t+1-t_{L}}^{p}\left(k_{t+1}\right)\right]+E_{t}^{d}\left[V_{t+1-t_{L}}^{d}\left(k_{t+1}\right)\right]>C_{L}$, in which players do not settle. Suppose that the players settle in period $t$ with monetary transfer $x_{t}$. The plaintiff agrees only if $x_{t} \geq \beta E_{t}^{p}\left[V_{t+1-t_{L}}^{p}\left(k_{t+1}\right)\right]$, while the defendant agrees only if $-x_{t} \geq \beta\left(E_{t}^{d}\left[V_{t+1-t_{L}}^{d}\left(k_{t+1}\right)\right]-C_{L}\right)$. This requires $0=x_{t}-x_{t} \geq E_{t}^{p}\left[V_{t+1-t_{L}}^{p}\left(k_{t+1}\right)\right]+E_{t}^{d}\left[V_{t+1-t_{L}}^{d}\left(k_{t+1}\right)\right]-C_{L}$. This contradicts with $E_{t}^{p}\left[V_{t+1-t_{L}}^{p}\left(k_{t+1}\right)\right]+E_{t}^{d}\left[V_{t+1-t_{L}}^{d}\left(k_{t+1}\right)\right]>C_{L}$, which proves that the players will not settle at $t$. Hence, the continuation value of each players at the beginning of date $t$ will be

$$
\begin{aligned}
V_{t-t_{L}}^{p}\left(k_{t}\right) & =\beta E_{t}^{p}\left[V_{t+1-t_{L}}^{p}\left(k_{t+1}\right)\right], \\
V_{t-t_{L}}^{d}\left(k_{t}\right) & =\beta\left(E_{t}^{d}\left[V_{t+1-t_{L}}^{d}\left(k_{t+1}\right)\right]-C_{L}\right) .
\end{aligned}
$$

Now, consider the case of $E_{t}^{p}\left[V_{t+1-t_{L}}^{p}\left(k_{t+1}\right)\right]+E_{t}^{d}\left[V_{t+1-t_{L}}^{d}\left(k_{t+1}\right)\right] \leq C_{L}$, in which players settle. Both players accepts an offer if it gives them at least their continuation value. If the plaintiff is recognized as a proposer, she chooses to offer $x_{t}=\beta\left(E_{t}^{d}\left[V_{t+1-t_{L}}^{d}\left(k_{t+1}\right)\right]-C_{L}\right)$, the defendant's continuation value. This is because the plaintiff's settlement offer is larger than her continuation value, i.e., $-x_{t}=-\beta\left(E_{t}^{d}\left[V_{t+1-t_{L}}^{d}\left(k_{t+1}\right)\right]+C_{L}\right) \geq \beta E_{t}^{p}\left[V_{t+1-t_{L}}^{p}\left(k_{t+1}\right)\right] . \quad$ I can apply the same argument for the case in which the defendant is the proposer. Thus, in equilibrium, the proposer offers the continuation value of the opponent, and the opponent accepts. The continuation value of each player at the beginning of date $t$ is written as

$$
\begin{aligned}
& V_{t-t_{L}}^{p}\left(k_{t}\right)=\phi \beta\left(-E_{t}^{d}\left[V_{t+1-t_{L}}^{d}\left(k_{t+1}\right)\right]+C_{L}\right)+(1-\phi) \beta\left(E_{t}^{p}\left[V_{t+1-t_{L}}^{p}\left(k_{t+1}\right)\right]\right) \\
& V_{t-t_{L}}^{d}\left(k_{t}\right)=\phi \beta\left(E_{t}^{d}\left[V_{t+1-t_{L}}^{d}\left(k_{t+1}\right)\right]-C_{L}\right)+(1-\phi) \beta\left(-E_{t}^{p}\left[V_{t+1-t_{L}}^{p}\left(k_{t+1}\right)\right]\right) .
\end{aligned}
$$

Combining both cases, the argument presented above proves the following proposition. 
Proposition 2 1. In the unique subgame perfect equilibrium, the payoff of the players at $t \in$ $\left\{t_{L}+1, \ldots, t_{L}+T\right\}$ in Phase $L$ are expressed as

$$
\begin{aligned}
V_{t-t_{L}}^{p}\left(k_{t}\right)= & \phi \beta \max \left\{-E_{t}^{d}\left[V_{t+1-t_{L}}^{d}\left(k_{t+1}\right)\right]+C_{L}, E_{t}^{p}\left[V_{t+1-t_{L}}^{p}\left(k_{t+1}\right)\right]\right\} \\
& +(1-\phi) \beta E_{t}^{p}\left[V_{t+1-t_{L}}^{p}\left(k_{t+1}\right)\right], \\
V_{t-t_{L}}^{d}\left(k_{t}\right)= & \phi \beta\left\{E_{t}^{d}\left[V_{t+1-t_{L}}^{d}\left(k_{t+1}\right)\right]-C_{L}\right\} \\
& +(1-\phi) \beta \max \left\{-E_{t}^{p}\left[V_{t+1-t_{L}}^{p}\left(k_{t+1}\right)\right], E_{t}^{d}\left[V_{t+1-t_{L}}^{d}\left(k_{t+1}\right)\right]-C_{L}\right\} .
\end{aligned}
$$

2. Given $k_{t}$ and $t_{L}$, players settle at $t \in\left\{t_{L}+1, \ldots-t_{L}+T\right\}$ in Phase $L$ iff

$$
E_{t}^{p}\left[V_{t+1-t_{L}}^{p}\left(k_{t+1}\right)\right]+E_{t}^{d}\left[V_{t+1-t_{L}}^{d}\left(k_{t+1}\right)\right] \leq C_{L} .
$$

3. Given that players settle at $t \in\left\{t_{L}+1, \ldots, t_{L}+T\right\}$ in Phase $L$, the payment is

$$
x_{t}=\left\{\begin{array}{cc}
\beta\left(-E_{t}^{d}\left[V_{t+1-t_{L}}^{d}\left(k_{t+1}\right)\right]+C_{L}^{d}\right) & \text { if the plaintiff is a proposer } \\
\beta E_{t}^{p}\left[V_{t+1-t_{L}}^{p}\left(k_{t+1}\right)\right] & \text { if the defendant is a proposer }
\end{array}\right.
$$

and the total legal cost incurred is $t_{L} C_{O}+t_{S} C_{L}$

This proposition characterizes the subgame perfect equilibrium in Phase $L$. Note that the identity of the proposer does not affect the settlement decision though it affects the compensation payment. This is because the players choose to settle if the joint surplus of settling today is larger than the joint surplus of continuing the case. The compensation payment depends on the identity of the proposer because the recognized proposer obtains all of the surplus. Though the plaintiff incurs no per-period legal cost, delaying agreement is still costly for him since he misses the benefits of the saving of the defendant's legal costs that indirectly increases compensation payment. Therefore, delaying agreement is costly for both players. However, the possibility of learning new information

makes delay valuable, since this information enhances the probability of a settlement, which in turn generates positive surplus for both players. This fundamental trade-off plays an important role in the equilibrium characterization and is a key determinant of the timing of settlement.

\subsubsection{Phase $O$ (Pre-Litigation Phase)}

Let $W_{t}^{i}\left(k_{t}\right)$ denote the continuation value for player $i \in\{p, d\}$ at the beginning of date $t$ in Phase $O$ with information state $k_{t}$. Again, I start from the last stage of Phase $O$ subgame. The maximum number of periods in Phase $O$ is $\bar{T}$, after which the claim by the plaintiff loses its value due to the 
statute of limitation. Hence, each player has continuation payoff of 0 at date $\bar{T}+1$, i.e.,

$$
W_{\bar{T}+1}^{p}\left(k_{\bar{T}+1}\right)=W_{\bar{T}+1}^{d}\left(k_{\bar{T}+1}\right)=0 .
$$

I obtain $W_{t}^{i}\left(k_{t}\right)$ by applying backward induction and having (3) as final values. In Phase $O$, the plaintiff has an option of litigating a case at any date $t \in\{0, \ldots, \bar{T}\}$. Solving the value function in Proposition 2 up to the first period in Phase $L$, I can obtain the continuation value of the Phase $L$ subgame, $V_{1}^{i}\left(k_{t}\right)$. Note that this continuation value does not depend on the date of litigation $t_{L}$ itself, but does depend on the information state $k_{t}$ at period $t$.

The plaintiff will choose to litigate at the end of date $t$ if and only if

$$
E_{t}\left[V_{1}^{p}\left(k_{t+1}\right)\right] \geq E_{t}\left[W_{t+1}^{p}\left(k_{t+1}\right)\right]
$$

Hence, the continuation value for the plaintiff at the end of date $t$ is written as

$$
Y_{t}^{p}\left(k_{t}\right)=\beta \max \left\{E_{t}\left[V_{1}^{p}\left(k_{t+1}\right)\right], E_{t}\left[W_{t+1}^{p}\left(k_{t+1}\right)\right]\right\},
$$

while the continuation value for the defendant depends on the litigation decision by the plaintiff and is written as

$$
Y_{t}^{d}\left(k_{t}\right)=\left\{\begin{array}{cl}
\beta\left(E_{t}\left[V_{1}^{d}\left(k_{t+1}\right)\right]-C_{L}\right) & \text { if } E_{t}\left[V_{1}^{p}\left(k_{t+1}\right)\right] \geq E_{t}^{p}\left[W_{t+1}^{p}\left(k_{t+1}\right)\right] \\
\beta\left(E_{t}\left[W_{t+1}^{d}\left(k_{t+1}\right)\right]-C_{O}\right) & \text { if } E_{t}\left[V_{1}^{p}\left(k_{t+1}\right)\right]<E_{t}^{p}\left[W_{t+1}^{p}\left(k_{t+1}\right)\right] .
\end{array}\right.
$$

Now, I repeat an argument similar to that of the Phase $L$ regarding settlement decision. I consider two separate cases depending on whether the players will settle or continue the case.

First, consider the case of $Y_{t}^{p}\left(k_{t}\right)>-Y_{t}^{d}\left(k_{t}\right)$, in which players do not settle. Suppose that the players settle in period $t$ with monetary transfer $x$. The plaintiff agrees only if $x \geq Y_{t}^{p}\left(k_{t}\right)$, while the defendant agrees only if $-x \geq-Y_{t}^{d}\left(k_{t}\right)$. This requires $0=x-x \geq Y_{t}^{p}\left(k_{t}\right)-Y_{t}^{d}\left(k_{t}\right)$. This contradicts with $Y_{t}^{p}\left(k_{t}\right)>-Y_{t}^{d}\left(k_{t}\right)$, which proves that the players will not settle at $t$. Hence, the continuation value of each players at the beginning of date $t$ will be

$$
W_{t}^{i}\left(k_{t}\right)=Y_{t}^{i}\left(k_{t}\right)
$$

Now, consider the case of $Y_{t}^{p}\left(k_{t}\right) \leq-Y_{t}^{d}\left(k_{t}\right)$, in which players settle. Each player accepts an offer if and only if it gives him at least his continuation value. If player $i$ is recognized as the proposer, she offers $Y_{t}^{j}\left(k_{t}\right)$ to player $j$, which is $j$ 's continuation value. Thus, in equilibrium, a proposer $i$ offers to give $Y_{t}^{j}\left(k_{t}\right)$ to the opponent $j$, and $j$ accepts this offer. I can write the 
continuation value of each player at the beginning of date $t$ as

$$
\begin{aligned}
& W_{t}^{p}\left(k_{t}\right)=\phi\left[-Y_{t}^{d}\left(k_{t}\right)\right]+(1-\phi) Y_{t}^{p}\left(k_{t}\right), \\
& W_{t}^{d}\left(k_{t}\right)=\phi Y_{t}^{d}\left(k_{t}\right)+(1-\phi)\left[-Y_{t}^{p}\left(k_{t}\right)\right] .
\end{aligned}
$$

This proves the following proposition.

Proposition $3 \quad$ 1. In any subgame perfect equilibrium, the payoffs of the players at $t \in\{0, \ldots, \bar{T}\}$ in Phase $O$ are expressed as

$$
\begin{aligned}
& W_{t}^{p}\left(k_{t}\right)=\phi \max \left\{-Y_{t}^{d}\left(k_{t}\right), Y_{t}^{p}\left(k_{t}\right)\right\}+(1-\phi) Y_{t}^{p}\left(k_{t}\right), \\
& W_{t}^{d}\left(k_{t}\right)=\phi Y_{t}^{d}\left(k_{t}\right)+(1-\phi) \max \left\{-Y_{t}^{p}\left(k_{t}\right), Y_{t}^{d}\left(k_{t}\right)\right\} .
\end{aligned}
$$

2. Given $k_{t}$, players settle at $t \in\{0, \ldots, \bar{T}\}$ in Phase $O$ iff

$$
Y_{t}^{p}\left(k_{t}\right)+Y_{t}^{d}\left(k_{t}\right) \leq 0 \text {. }
$$

3. Given $k_{t}$, the plaintiff litigates at $t \in\{0, \ldots, \bar{T}\}$ in Phase $O$ iff

$$
E_{t}\left[V_{1}^{p}\left(k_{t+1}\right)\right] \geq E_{t}\left[W_{t+1}^{p}\left(k_{t+1}\right)\right]
$$

4. Given that players settle at $t \in\{0, \ldots, \bar{T}\}$ in Phase $O$, the payment is

$$
x_{t}=\left\{\begin{array}{cl}
-Y_{t}^{d}\left(k_{t}\right) & \text { if the plaintiff is a proposer } \\
Y_{t}^{p}\left(k_{t}\right) & \text { if the defendant is a proposer }
\end{array}\right.
$$

and the total legal cost incurred is $t_{S} C_{O}$.

This proposition characterizes the subgame perfect equilibrium in Phase $O$. The mechanics of the settlement decision are exactly the same as for the characterization for Phase $L$. The only difference is that the cost of delay and the possibility of learning in the next period depends on the plaintiff's decision to file or not at the end of each period.

The decision to file a lawsuit by the plaintiff is also derived from a trade-off between the cost of delay and the possibility of learning. The cost of delaying filing has two components. One is the per-period legal cost of the pre-litigation phase, since the total length of the underlying game becomes one period longer if filing is delayed by one period. Even though the plaintiff incurs no legal cost per period, this delay still matters since saving of the defendant's legal cost results in higher compensation payment to the plaintiff. The second component is the cost of delay due to 
discounting. The plaintiff prefers to obtain the continuation value of the Phase $L$ subgame earlier, since a one-period delay in filing costs $\operatorname{him}(1-\beta) V_{1}^{p}(\cdot)$ when no information arrives. The benefit of delaying filing by one period is that the parties have one more period to obtain new information and hence reach an agreement. Thus, the plaintiff prefers to stay in Phase $O$ longer if $C_{O}$ is small and $\beta$ is large, while low $\lambda_{O t}$ provides an incentive for the plaintiff to file early.

\section{Data}

In Florida, a statute on professional liability claims requires medical malpractice insurers to file a report on all of their closed claims once the claim is resolved. The reports are collected by the Florida Department of Financial Services, the insurance regulator of the Florida state government. The report contains detailed information on the dispute resolution process, as well as individual case characteristics. The information on the dispute resolution process includes important dates (calender date of occurrence, initial claim, filing of lawsuit, resolution either by settlement or by court judgement), settlement payments (or award by the court in case of resolution by court judgment), and total legal costs incurred by the defendants. The information on case characteristics includes patient characteristics (such as age and sex), defendant characteristics (such as defendant type, specialty, and insurance policy), and the characteristics of injury (such as severity and place of occurrence). Hence, this data set contains detailed information on all the variables of interest, i.e., if and when a lawsuit is filed, whether or not the case is settled out of court, the time to resolution, the legal costs incurred and the terms of settlement.

My sample of observations consists of 3,845 claims against physicians ${ }^{11}$ which are resolved between October 1985 and July 1999. ${ }^{12}$ Following Sieg (2000), I restrict attention to cases with the defendant's legal cost exceeding $\$ 1,000$ and which are not dropped during the litigation process. ${ }^{13}$ Since the timing and disposition of cases are very different depending on the severity of the injury, I restrict attention to the cases in which injuries resulted in permanent major damage to death of the patient.

Tables 1 and 2 show the descriptive statistics of all the variables I use for estimation. In my data, $87.4 \%$ of the cases are settled by parties rather than facing judgment by the court. These cases are either settled after filing a lawsuit (75.3\%) or settled without filing a lawsuit (12.3\%). Only $12.6 \%$ of all the cases are resolved by a court judgment. Where this happens, the defendants are three times more likely to win the judgment (award is zero). Mean compensation payments are similar for the cases that are settled after filing a lawsuit and those that are settled without filing

\footnotetext{
${ }^{11}$ Claims against hospitals, HMOs, dentists, ambulance surgical centers, and crisis stabilization units are excluded from my sample.

${ }^{12}$ During this period, there were no major changes in state law pretaining to resolution of medical malpractice disputes.

${ }^{13}$ This procedure eliminates small and frivolous cases.
} 


\begin{tabular}{|c|c|c|c|c|}
\hline & $\begin{array}{c}\text { Number of } \\
\text { Observations }\end{array}$ & $\begin{array}{l}\text { Resolution } \\
\text { Probability }\end{array}$ & $\begin{array}{c}\text { Mean } \\
\text { Compensation }\end{array}$ & $\begin{array}{l}\text { Mean Defense } \\
\text { Legal Cost }\end{array}$ \\
\hline $\begin{array}{l}\text { Settled } \\
\text { without Lawsuit }\end{array}$ & 472 & 0.123 & $\begin{array}{c}314,266 \\
(303,917)\end{array}$ & $\begin{array}{c}9,047 \\
(15,014)\end{array}$ \\
\hline $\begin{array}{l}\text { Settled } \\
\text { after Lawsuit }\end{array}$ & 2,887 & 0.751 & $\begin{array}{l}303,402 \\
(379,909\end{array}$ & $\begin{array}{c}53,989 \\
(88,887)\end{array}$ \\
\hline $\begin{array}{l}\text { Resolved by Judgment } \\
\text { with Positive Award }\end{array}$ & 127 & 0.033 & $\begin{array}{c}541,832 \\
(620,722)\end{array}$ & $\begin{array}{c}127,966 \\
(113,147)\end{array}$ \\
\hline $\begin{array}{l}\text { Resolved by Judgment } \\
\text { with No Award }\end{array}$ & 359 & 0.093 & $\begin{array}{c}0 \\
(0)\end{array}$ & $\begin{array}{c}83,182 \\
(87,268)\end{array}$ \\
\hline Total & 3,845 & 1.000 & $\begin{array}{c}284,283 \\
(377,401)\end{array}$ & $\begin{array}{c}53,641 \\
(87,159)\end{array}$ \\
\hline
\end{tabular}

Compensation payments and legal costs are measured in 2000 dollars. Numbers in parentheses provides standard deviations.

Table 1: Descriptive Statistics I - Resolution Probability, Payments and Legal Costs

a lawsuit (around $\$ 300,000$ ).

Legal costs for defendants substantially differ across modes of resolution. The legal fee for the defendants' lawyers are usually charged by time. Hence, it is not surprising to find that the mean of the defence legal costs is strongly correlated with the mean time to resolution displayed in Table 2. Mean of defence legal costs for the cases settled without a lawsuit is about one-fifth of the mean of these cases corresponding to much shorter mean time to resolution in Table 2. The cases settled after filing a lawsuit have a significantly higher mean cost $(\$ 53,989)$ compared with the settled cases without a lawsuit $(\$ 9,047)$. Among the cases resolved by court judgement, mean defense costs are more than $50 \%$ higher for the cases won by the plaintiffs than the cases won by the defendants, which again corresponds to the longer time to resolution.

Mean time to filing a lawsuit, which corresponds to the periods spent in the pre-litigation phase, is similar for the settled cases and cases resolved by court judgment. The time to resolution differ between the cases settled after filing and the cases resolved by the judgment results from the difference in time to resolution after filing lawsuit. The cases settled without a lawsuit, which correspond to settlement in pre-litigation phase, spend longer period in pre-litigation phase than the filed cases on average.

Figures 2 offers more detailed description of statistics on the time to filing and the time to settlement in pre-litigation phase. Figure 2 provides the histogram of filing and settlement without lawsuit. Note that the sum of the fractions for filing and settlement without lawsuit add up to one 


\begin{tabular}{lccc}
\hline \hline & $\begin{array}{c}\text { Time to } \\
\text { Filing (quarters) }\end{array}$ & $\begin{array}{c}\text { Time to Resolution } \\
\text { after Filing (quarters) }\end{array}$ & $\begin{array}{c}\text { Total Time to } \\
\text { Resolution (quarters) }\end{array}$ \\
\hline Settled & - & - & 3.23 \\
without Filing & 2.48 & 7.45 & $(2.41)$ \\
Settled & $(2.26)$ & $(4.55)$ & 9.93 \\
after Filing & 2.69 & 11.41 & $(5.16)$ \\
Resolved by Judgment & $(2.67)$ & $(6.61)$ & 14.10 \\
with Positive Award & 2.50 & 9.69 & $(7.17)$ \\
Resolved by Judgment & $(3.21)$ & $(5.17)$ & 12.19 \\
with No Award & 2.58 & 6.88 & $(6.24)$ \\
Total & $(2.41)$ & $(5.19)$ & 9.46 \\
& & & $(5.69)$ \\
\hline
\end{tabular}

The numbers in parentheses provide standard deviations.

Table 2: Descriptive Statistics II - Timings

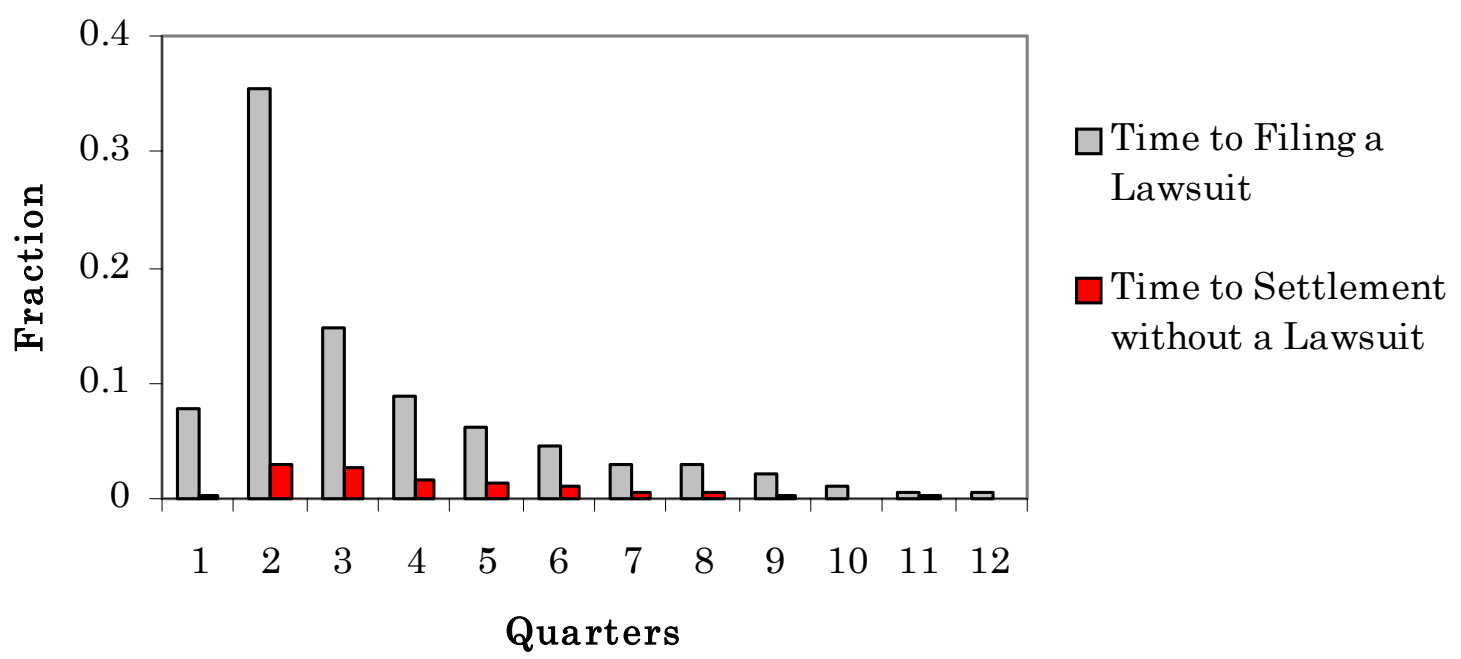

Fraction of time to filing a lawsuit and time to settle without a lawsuit add up to one. This is because cases are either 1) resolved after a lawsuit is filed or 2) settled without a lawsuit.

Figure 2: Histogram of Time to Filing and Settlement in Pre-Litigation Phase 


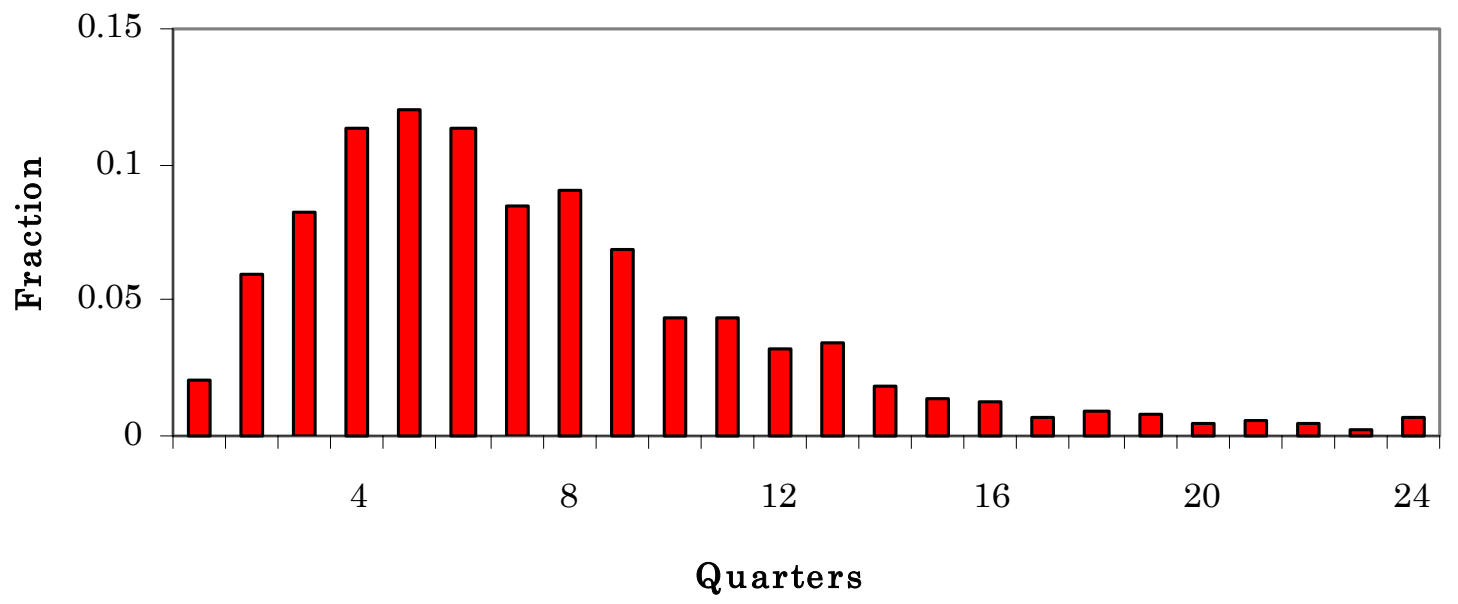

Time is counted from the date of filing a lawsuit in quarters. Cases exceeding 6 years are counted in the bin of 24 quarter.

Figure 3: Histogram of Time to Settlement after Filing

because each case is either filed or settled without lawsuit. In Florida, the period for the statute of limitation regarding a medical malpractice cases is two years. Hence, more than $95 \%$ of the cases are filed or settled without filing a lawsuit before the ninth quarter. ${ }^{14}$

Fraction of cases filing lawsuits in pre-litigation phase and that of cases settling without lawsuits have the common pattern that the hazard rate increases significantly at the second quarter and gradually increases over time. Corresponding to a high hazard rate after the second quarter, the histogram has more than $35 \%$ of cases filed in second quarter before the fraction declines rapidly over time. Regarding the time to settlement without a lawsuit, the decline after the second quarter is much slower as a result of the lower hazard rate.

Figures 3 presents more details on the time to settlement after filing a lawsuit. The hazard rate increases over time similar to the time to filing and the time to settlement without a lawsuit. $90 \%$ of cases are settled in 13 quarters, and only less than $5 \%$ of cases are settled after 16 quarters.

Compensation payments have very high variance. Figure 4 presents the histogram of (log) compensation payments from the defendant to the plaintiff. About $9 \%$ of the cases which concluded with judgment in favor of the defendant have zero payments. The amount of positive payments have very high variance, and the shape of the distribution is close to log-normal distribution. More than half of the cases are between $\$ 98,700$ and $\$ 729,400$. The distribution for the cases judged with positive award is also similar to the log-normal distribution, while the mean and variance are

\footnotetext{
${ }^{14}$ The remaining cases may be due, for example, to invervening medical complications that entail an automatic extension of the statute of limitations.
} 
Figure 4: Histogram of Payments
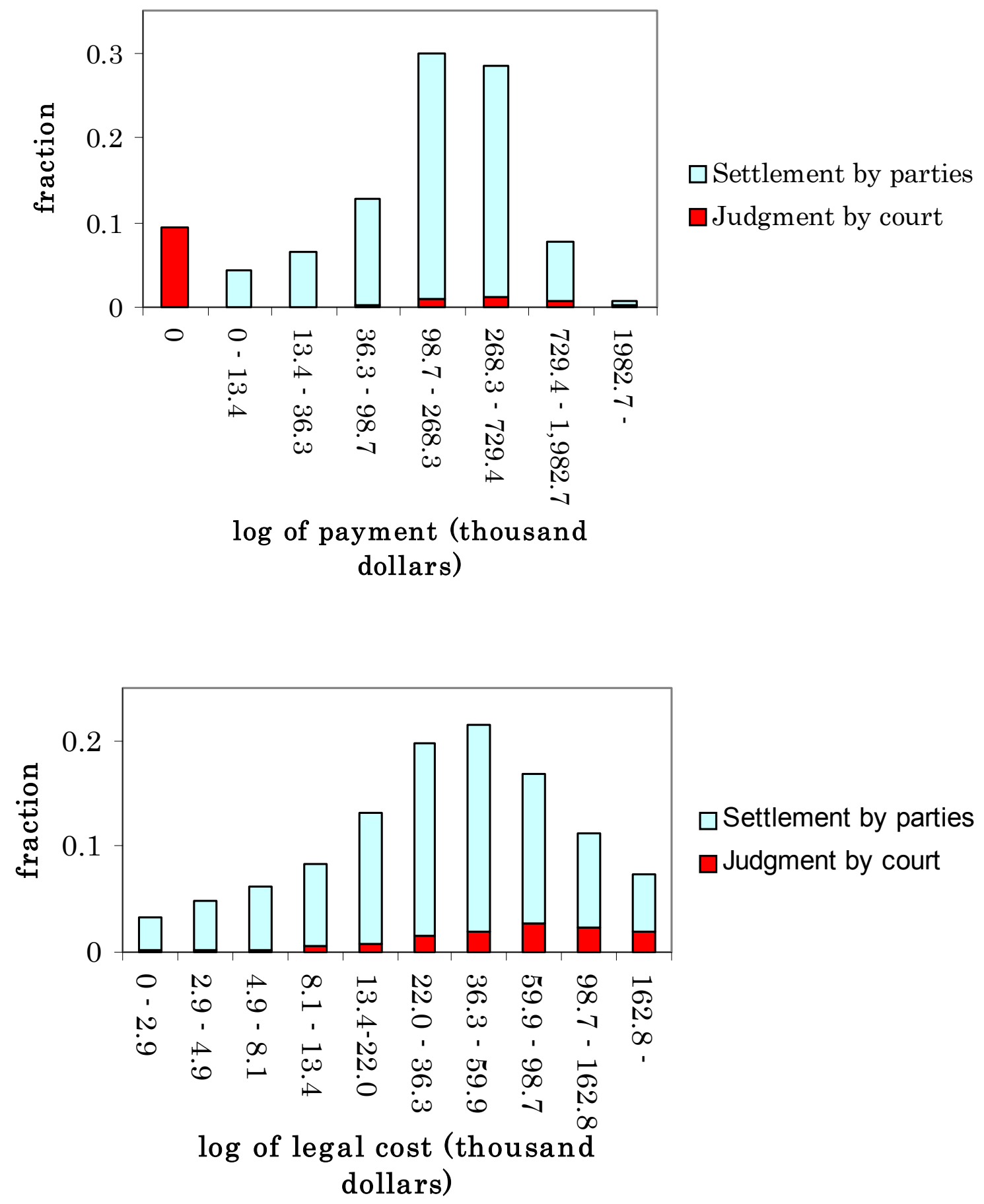

Figure 5: Histogram of Defence Legal Costs 
much larger.

Similar to that of compensation payments, the distribution of legal costs is close to a log-normal distribution. As clearly seen from Figure 5, the distribution of cost of the cases resolved by court judgment have much higher costs compared with the distribution of the other cases. The cases settled tend to have much lower cost compared with the cases resolved by court judgments.

\section{Econometric Specification}

Calculating Conditional Probabilities for Decisions In Section 2, I characterized the equilibrium outcome on the time, mode, cost, and terms of settlement, as well as the time of filing a lawsuit (if a lawsuit is filed). However, the outcomes are contingent on the realization of the state of information $k_{t}=\left(n_{t}, m_{t}\right) \in\{0, \ldots, t\} \times\{0, \ldots, t\}$ which is not observable to the econometrician. Thus, from the perspective of the econometrician, the litigation timing $t_{L}$, the settlement timing $t_{S}$, the compensation payment $x$, and the total legal cost are all random variables because they depend on the (unobservable) realization of $k_{t}$. Hence, I first compute the conditional probability of observing the realization of such random variables in order to compute the likelihood contribution.

Let $d_{t}^{S O}\left(n_{t}, m_{t}\right), d_{t}^{S L}\left(n_{t}, m_{t}\right)$, and $d_{t}^{F I}\left(n_{t}, m_{t}\right)$ denote the indicator function respectively for settlement in Phase $O$, settlement in Phase $L$, and filing of a lawsuit at period $t$. Using the results of Propositions 2 and 3, these indicator functions are written as

$$
\begin{aligned}
d^{S O}{ }_{t}\left(n_{t}, m_{t}\right) & =I\left\{Y_{t}^{p}\left(n_{t}, m_{t}\right)+Y_{t}^{d}\left(n_{t}, m_{t}\right)<0\right\}, \\
d^{S L}{ }_{t}\left(n_{t}, m_{t}, t_{L}\right) & =I\left\{E_{t} V_{t-t_{L}}^{p}\left(n_{t+1}, m_{t+1}\right)+E_{t} V_{t-t_{L}}^{d}\left(n_{t+1}, m_{t+1}\right)-C_{L}<0\right\}, \\
d^{F I}{ }_{t}\left(n_{t}, m_{t}\right) & =I\left\{E_{t} V_{1}^{p}\left(n_{t+1}, m_{t+1}\right)>E_{t} W_{t+1}^{p}\left(n_{t+1}, m_{t+1}\right)\right\},
\end{aligned}
$$

where $d_{t}^{S O}\left(n_{t}, m_{t}\right)=1, d_{t}^{S L}\left(n_{t}, m_{t}, t_{L}\right)=1, d_{t}^{F I}\left(n_{t}, m_{t}\right)=1$ indicate settlement in Phase $O$ and in Phase $L$, and litigation at period $t$ given $\left(n_{t}, m_{t}\right),\left(n_{t}, m_{t}, t_{L}\right)$, and $\left(n_{t}, m_{t}\right)$ while 0 otherwise. In computing equilibrium, we assume the rates of information arrival as $\lambda_{O t}=\lambda_{O 0}+\lambda_{O 1} t$ and $\lambda_{L t}=\lambda_{L 0}+\lambda_{L 1} t$. Let $q_{t}^{O}\left(n_{t}, m_{t}\right)$ denote the probability of being in state $k_{t}=\left(n_{t}, m_{t}\right) \in\{0, \ldots, t\}$ $\times\{0, \ldots, t\}$ in Phase $O$, and let $q_{t}^{L}\left(n_{t}, m_{t}, t_{L}\right)$ denote the probability of being in state $k_{t}$ in Phase $L$ given the litigation date of $t_{L}<t$. I can compute $q_{t}^{O}$ recursively as follows:

$$
\begin{aligned}
q_{0}^{O}(0,0)= & 1 \\
q_{t}^{O}(n, m)= & \lambda_{O t} \pi q_{t-1}^{O}(n-1, m-1)\left[1-d_{t}^{S O}(n-1, m-1)\right]\left[1-d_{t}^{F I}(n-1, m-1)\right] \\
& +\lambda_{O t}(1-\pi) q_{t-1}^{O}(n-1, m)\left[1-d_{t}^{S O}(n-1, m)\right]\left[1-d_{t}^{F I}(n-1, m)\right] \\
& +\left(1-\lambda_{O t}\right) q_{t-1}^{O}(n, m)\left[1-d_{t}^{S O}(n, m)\right]\left[1-d_{t}^{F I}(n, m)\right] .
\end{aligned}
$$


The initial condition for $q_{t}^{L}$ is $q_{t_{L}}^{L}$, which can be written as

$$
q_{t_{L}}^{L}\left(n, m, t_{L}\right)=\sum_{n_{t_{L}}=0}^{t_{L}} \sum_{m_{t_{L}}=0}^{t_{L}} q_{t_{L}}^{O}\left(n_{t_{L}}, m_{t_{L}}\right) d_{t}^{F I}\left(n_{t_{L}}, m_{t_{L}}\right)
$$

I can compute $q_{t}^{L}$ recursively for $t>t_{L}$ as follows:

$$
\begin{aligned}
q_{t}^{L}\left(n, m, t_{L}\right)= & \lambda_{L t} \pi q_{t-1}^{L}\left(n-1, m-1, t_{L}\right)\left[1-d_{t}^{S L}\left(n-1, m-1, t_{L}\right)\right] \\
& +\lambda_{L t}(1-\pi) q_{t-1}^{L}\left(n-1, m, t_{L}\right)\left[1-d_{t}^{S L}\left(n-1, m, t_{L}\right)\right] \\
& +\left(1-\lambda_{L t}\right) q_{t-1}^{L}\left(n, m, t_{L}\right)\left[1-d_{t}^{S L}\left(n, m, t_{L}\right)\right]
\end{aligned}
$$

Let $l=\{F I L E, N O F I L E\}$ denote if a case is litigated $(l=F I L E)$ or not $(l=$ NOFILE), and $s \in\{S E T T L E, J U D G E\}$ denote if the case is settled $(s=S E T T L E)$ or reaches judgment by the court $(s=J U D G E)$. A case is resolved either by settlement with lawsuit $((l, s)=$ (FILE, SETTLE)), by settlement without lawsuit $((l, s)=((N O F I L E, S E T T L E))$, or by judgement of the court $((l, s)=(F I L E, J U D G E))$ on equilibrium path. With this notation, the probability that the econometrician observes litigation at date $t_{L}$ can be written as

$$
\operatorname{Pr}(F I L E) \times \operatorname{Pr}\left(t_{L} \mid F I L E\right)=\sum_{n_{t_{L}}=0}^{t_{L}} \sum_{m_{t_{L}}=0}^{t_{L}} q_{t_{L}}^{O}\left(n_{t_{L}}, m_{t_{L}}\right) d_{t}^{F I}\left(n_{t_{L}}, m_{t_{L}}\right)
$$

where $q_{t_{L}}^{O}\left(n_{t_{L}}, m_{t_{L}}\right)$ is the probability of reaching state $k_{t_{L}}=\left(n_{t_{L}}, m_{t_{L}}\right)$ in period $t_{L}$ and $d_{t}^{F I}\left(n_{t_{L}}, m_{t_{L}}\right)$ is the indicator of filing a lawsuit at $t_{L}$ given the state $k_{t_{L}}$. Settlement in Phase $L$ occurs only after litigation in Phase $O$. Thus, the probability of settlement in Phase $L$ conditional on litigation at Phase $L$ is written as

$$
\operatorname{Pr}\left(t_{S}, S E T T L E \mid t_{L}, F I L E\right)=\sum_{n_{t_{S}}=0}^{t_{S}} \sum_{m_{t_{S}}=0}^{t_{S}} q_{t_{S}}^{L}\left(n_{t_{S}}, m_{t_{S}}, t_{L}\right) d_{t}^{S L}\left(n_{t_{S}}, m_{t_{S}}, t_{L}\right),
$$

where $q_{t_{S}}^{L}\left(n_{t_{S}}, m_{t_{S}}, t_{L}\right)$ is the probability of reaching state $k_{t_{L}}=\left(n_{t_{L}}, m_{t_{L}}\right)$ in period $t_{S}$ given the case is litigated at $t_{L}$ and $d_{t}^{S L}\left(n_{t_{S}}, m_{t_{S}}, t_{L}\right)$ is the indicator of settlement in period $t_{S}$ at state $\left(n_{t_{S}}, m_{t_{S}}\right)$ given the case is litigated at $t_{L}$. The probability of reaching judgment can be calculated similarly. If players do not settle for the whole period in Phase $L$ between $t_{L}+1$ and $t_{L}+T$, the case reaches judgment $(s=J U D G E)$ by the court. Hence, I can write the probability of reaching judgement as

$$
\operatorname{Pr}\left(J U D G E \mid t_{L}, F I L E\right)=\sum_{n_{T}=0}^{T} \sum_{m_{T}=0}^{T} q_{T}^{L}\left(n_{T}, m_{T}, t_{L}\right)\left[1-d_{t}^{S L}\left(n_{T}, m_{T}, t_{L}\right)\right]
$$


In some cases, players may settle in Phase $O$ and I do not observe litigation in such a case. I can write the probability of observing settlement at date $t_{S}$ without litigation $(l=N O F I L E)$ as

$$
\operatorname{Pr}\left(t_{S}, S E T T L E \mid \emptyset, N O F I L E\right)=\sum_{n_{t_{S}}=0}^{t_{S}} \sum_{m_{t_{S}}=0}^{t_{S}} q_{t_{S}}^{O}\left(n_{t_{S}}, m_{t_{S}}\right) d_{t}^{S O}\left(n_{t_{S}}, m_{t_{S}}\right)
$$

where $q_{t_{S}}^{O}\left(n_{t_{S}}, m_{t_{S}}\right)$ is the probability of reaching state $k_{t_{S}}=\left(n_{t_{S}}, m_{t_{S}}\right)$ in period $t_{S}$ and $d_{t}^{S O}\left(n_{t_{S}}, m_{t_{S}}\right)$ is the indicator of filing lawsuit at $t_{S}$ given the state $k_{t_{S}}$.

Another piece of information unobservable to the econometrician is the identity of the proposer. The identity of the proposer on the settlement day affects the payment as shown by both Propositions 1 and 2. Let $d^{p}$ and $d^{d}$ be the indicator function such that

$$
\begin{aligned}
d^{p}\left(n_{t}, m_{t}, x, t_{S}, t_{L}, F I L E\right) & =I\left\{x=-\beta\left[E_{t} V_{t_{S}-t_{L}+1}^{d}\left(n_{t_{S}+1}, m_{t_{S}+1}\right)+C_{L}\right]\right\}, \\
d^{d}\left(n_{t}, m_{t}, x, t_{S}, t_{L}, F I L E\right) & =I\left\{x=\beta E_{t}\left[V_{t_{S}-t_{L}+1}^{p}\left(n_{t_{S}+1}, m_{t_{S}+1}\right)\right]\right\}, \\
d^{p}\left(n_{t}, m_{t}, x, t_{S}, \emptyset, \text { NOFILE }\right) & =I\left\{x=-Y_{t}^{d}\left(n_{t_{S}}, m_{t_{S}}\right)\right\}, \\
d^{d}\left(n_{t}, m_{t}, x, t_{S}, \emptyset, \text { NOFILE }\right) & =I\left\{x=Y_{t}^{p}\left(n_{t_{S}}, m_{t_{S}}\right)\right\} .
\end{aligned}
$$

Because the nature chooses the plaintiff as a proposer with probability $\phi$ and the defendant with probability $1-\phi$, the probability of observing payment $x$, given the settlement date $t_{S}$ and the litigation date $t_{L}$, is

$$
\begin{aligned}
& \operatorname{Pr}\left(x \mid t_{S}, S E T T L E, t_{L}, F I L E\right) \\
= & \sum_{n_{t_{S}}=0}^{t_{S}} \sum_{m_{t_{S}}=0}^{t_{S}} \phi q_{t_{S}}^{L}\left(n_{t_{S}}, m_{t_{S}}, t_{L}\right) d^{p}\left(n_{t_{S}}, m_{t_{S}}, x, t_{S}, t_{L}, F I L E\right) \\
& +\sum_{n_{t_{S}}=0}^{t_{S}} \sum_{m_{t_{S}}=0}^{t_{S}}(1-\phi) q_{t_{S}}^{L}\left(n_{t_{S}}, m_{t_{S}}, t_{L}\right) d^{d}\left(n_{t_{S}}, m_{t_{S}}, x, t_{S}, t_{L}, F I L E\right) .
\end{aligned}
$$

Similarly, I can express the probability of payment with settlements without lawsuit in Phase $O$ as

$$
\begin{aligned}
& \operatorname{Pr}\left(x \mid t_{S}, \text { SETTLE, } \emptyset, \text { NOFILE }\right) \\
= & \sum_{n_{t_{S}}=0}^{t_{S}} \sum_{m_{t_{S}}=0}^{t_{S}} \phi q_{t_{S}}^{O}\left(n_{t_{S}}, m_{t_{S}}\right) d^{p}\left(n_{t_{S}}, m_{t_{S}}, x, t_{S}, \emptyset, \text { NOFILE }\right) \\
& +\sum_{n_{t_{S}}=0}^{t_{S}} \sum_{m_{t_{S}}=0}^{t_{S}}(1-\phi) q_{t_{S}}^{O}\left(n_{t_{S}}, m_{t_{S}}\right) d^{d}\left(n_{t_{S}}, m_{t_{S}}, x, t_{S}, \emptyset, \text { NOFILE }\right) .
\end{aligned}
$$

If a case reaches judgement, the identity of the proposer does not matter because there is no 
bargaining taking place. The defendant pays the amount of jury award if he prevails, and makes no payments otherwise. Hence, I can express the density of the payment in judgment as

$$
\operatorname{Pr}\left(x \mid t_{S}, J U D G E, t_{L}, F I L E\right)=\left\{\begin{array}{cl}
1-\pi & \text { if } x=0 \\
\pi \operatorname{Pr}\left(x=\beta^{-t} V\right) & \text { if } x>0
\end{array}\right.
$$

This completes the computation of conditional probabilities.

Unobserved Heterogeneity I admit unobserved heterogeneity in several dimension. Given two cases that are resolved by court judgment, the time to judgment $T$ significantly differs across cases. For example, congestion in the legal system in a particular jurisdiction affects the time to judgement $T$. Hence, I need to assume an unobserved heterogeneity on the exogenous parameter $T$. I assume $T$ to follow a negative binomial distribution which is a flexible distribution with discrete support. I denote the cumulative distribution function $(\mathrm{CDF})$ of $T$ by $F_{T}(\cdot)$ with parameters $\psi_{0 \bar{T}}$ and $\psi_{1 \bar{T}}$.

The statute of limitation period $\bar{T}$, which is also exogenous in the model, also differs across cases though the statute of limitation date for medical malpractice litigation in Florida is set at 2 years. The legally determined statute of limitation period is not the actual length of time player can bargain without filing a lawsuit. The statute of limitation is legally counted from the date of the occurrence of incident, but the bargaining does not necessarily begin on the date of occurrence. For example, a plaintiff may begin bargaining 8 months after the occurrence of the incident, which leaves him 16 months before filing if the legal length of the statute of limitation is 24 months. I assume $\bar{T}$ to follow a negative binomial distribution which is a flexible distribution with discrete support. I denote their CDFs by $F_{\bar{T}}(\cdot)$ with parameters $\psi_{0 T}$ and $\psi_{1 T}$.

Similarly, cases that are resolved by court judgment may also have very different potential jury awards $V$ depending on the unobserved characteristics of the case, composition of the juries, and other factors. Hence, I consider unobserved heterogeneity in $V$, and assume that $V$ follows a log-normal distribution $F_{V}(\cdot)$ with mean and variance denoted by $\mu_{V}$ and $\sigma_{V}^{2}$.

The per-period legal cost of the defendant also differs across cases due to factors such as the law firm the defendant employs or some unobserved characteristics. Given a case, however, the per-period legal cost after filing a lawsuit is most likely to increase due to the increase in the hours worked by the lawyers to prepare more documentations. Hence, I reparametrize $C_{L}$ by a new parameter $\alpha$ so that $C_{L}=(1+\alpha) C_{O}$. Since the degree of the increase of the per-period legal cost depends on the characteristics of the case, as well as the law firm employed for the case, I assume $\alpha$ to have unobserved heterogeneity. Therefore, I consider unobserved heterogeneity in both prelitigation and litigation phase legal cost, and assume them to follow log-normal distributions whose cumulative distribution functions are denoted by $F_{C}(\cdot)$ and $F_{\alpha}(\cdot)$, with parameters $\mu_{C}, \sigma_{C}^{2}, \mu_{\alpha}, \sigma_{\alpha}^{2}$ 
respectively. For notational convenience, I denote the realization of unobserved heterogeneity by $Z=\left\{C_{O}, \alpha, V, T, \bar{T}\right\}$.

Step 1: Estimation of Cost Parameters I employ a two step procedure to estimate the model. I first estimate the parameters regarding per period costs $C_{O}$ and $C_{L}$, then estimate the model in the second step. I can separate the estimation of the cost parameters from the estimation of the model. This is because total cost depends only on the outcome of durations of being in the pre-litigation phase and that in litigation phase, i.e.

$$
C=\left\{\begin{array}{cl}
t_{S} C_{O} & \text { if } l=\text { NOFILE } \\
t_{L} C_{O}+\left(t_{S}-t_{L}\right)(1+\alpha) C_{O} & \text { if } l=\text { FILE }
\end{array}\right.
$$

In Step 1, I estimate the parameters for the distributions $C_{O}$ and $C_{L}=(1+\alpha) C_{O}$, i.e. $\mu_{C}, \sigma_{C}^{2}, \mu_{\alpha}$, and $\sigma_{\alpha}^{2}$. I first estimate $\mu_{C}$ and $\sigma_{C}^{2}$ from the cases settled without litigation $l=N O F I L E$. For these cases, I can obtain the mean and variance of $\frac{C}{t_{S}}$ and recover $\mu_{C}$ and $\sigma_{C}^{2}$. Then, I use the estimated $\mu_{C}$ and $\sigma_{C}^{2}$ with the cases $l=F I L E$ to obtain the estimates of $\mu_{\alpha}$ and $\sigma_{\alpha}^{2}$. Appendix A explains the details of the identification and computation.

Step 2: Estimation of the Model I use the equilibrium characterization obtained in Propositions 1 and 2 to compute the likelihood contribution of each observation. Since I can compute the conditional probabilities of equilibrium decisions (as above), I can now construct the likelihood function. The contribution to the likelihood function of each observation in the sample is equal to the probability of observing the vector of endogenous events $\left(x, t_{S}, t_{L}, s, l\right)$ given the vector of the parameters $\Theta=\left\{\beta, \theta_{d}, \theta_{p}, \rho, \lambda_{A}, \lambda_{B}, \pi, \phi, F_{T}, F_{\bar{T}}, F_{C}, F_{\alpha}, F_{V}\right\}$. Because I consider unobserved heterogeneity in $Z=\left\{C_{O}, \alpha, V, T, \bar{T}\right\}$, I need to conduct a Monte Carlo integration over these variables $Z$ in order to obtain the likelihood which can be written as

$$
L\left(\Theta \mid x, t_{S}, s, t\right)=\iiint \iint \operatorname{Pr}\left(x, t_{S}, s, t_{L}, l \mid Z ; \gamma\right) d F_{C} d F_{\alpha} d F_{T} d F_{\bar{T}} d F_{V}
$$

where $\operatorname{Pr}\left(x, t_{S}, s, t_{L}, l \mid Z ; \Theta\right)$ is computed using the conditional probabilities computed above as follows: For the cases settled without filing a lawsuit, $\operatorname{Pr}\left(x, t_{S}, s, t_{L}, l \mid Z ; \Theta\right)$ is

$$
\begin{aligned}
& \operatorname{Pr}\left(x, t_{S}, s, t_{L}, l \mid Z ; \Theta\right) \\
=\operatorname{Pr}( & N O F I L E \mid Z, \Theta)) \times \operatorname{Pr}\left(t_{S} \mid \text { SETTLE, } \emptyset, \text { NOFILE, } Z, \Theta\right) \\
& \times \operatorname{Pr}\left(x \mid t_{S}, S E T T L E, \emptyset, \text { NOFILE }, Z, \Theta\right) .
\end{aligned}
$$


For the cases settled after filing a lawsuit, $\operatorname{Pr}\left(x, t_{S}, s, t_{L}, l \mid Z ; \Theta\right)$ is computed by

$$
\begin{aligned}
& \operatorname{Pr}\left(x, t_{S}, s, t_{L}, l \mid Z ; \Theta\right) \\
= & \operatorname{Pr}(F I L E \mid Z, \Theta) \times \operatorname{Pr}\left(t_{L} \mid F I L E, Z, \Theta\right) \times \operatorname{Pr}\left(S E T T L E \mid t_{L}, F I L E, Z, \Theta\right) \\
& \times \operatorname{Pr}\left(t_{S} \mid S E T T L E, t_{L}, F I L E, Z, \Theta\right) \times \operatorname{Pr}\left(x \mid t_{S}, S E T T L E, t_{L}, \text { NOFILE }, Z, \Theta\right),
\end{aligned}
$$

while for the cases resolved in court judgment I have

$$
\begin{aligned}
& \operatorname{Pr}\left(x, t_{S}, s, t_{L}, l \mid Z ; \Theta\right) \\
= & \operatorname{Pr}(F I L E \mid Z, \Theta) \times \operatorname{Pr}\left(t_{L} \mid F I L E, Z, \Theta\right) \\
& \times \operatorname{Pr}\left(J U D G E \mid t_{L}, F I L E, Z, \Theta\right) \times \operatorname{Pr}\left(x \mid J U D G E, t_{L}, F I L E, Z, \Theta\right) .
\end{aligned}
$$

I take the log of above probability and sum them over all the elements in the sample to obtain the log-likelihood.

\section{$5 \quad$ Results}

Estimates are presented in Table 3. As a result of estimation, I find that the model fits all aspect of the data well. In this section, I provide the fit of the model regarding the time to settlement and filing, as well as the compensation payments for different modes of resolution. In Figures 6 and 7, I present the fit of the model to the data on the time to settlement and filing. The model replicates the dynamic patterns of filing and settlement in pre-litigation very well as shown in Figure 6 . In particular, the model fits the data on the time to filing, which increase sharply in period 2 and decreases gradually, very well. Regarding settlement in the pre-litigation phase, the magnitude of the fraction is captured correctly. The model under-predicts by about 0.02 for the fraction in periods 3 and 4 . Figure 7 shows the fit of the model on the time to settlement after filing a lawsuit. The model captures the shape of the data, which increases for the first several period and then declines gradually. The difference between the predicted fractions of cases settling and the data in the first three periods and the last several periods may result from the linearity assumption on the rate of arrival. This assumption may have prevented the model from capturing some factors in the data.

Figures 8-10 present the fit of the model on the compensation payment. As shown in Figure 8 , the fit on payments for the cases resolved by court judgment is very good. The fraction of the cases in which the defendant prevails as well as the distribution for positive awards are pinned down exactly because parameter $\pi$ directly identifies this ratio. Figure 9 provides the fit of the model with respect to compensation payment for the cases settled after filing. The model replicates the shape of the data with fifth and sixth bins having the largest fractions. The fit of the highest three 


\begin{tabular}{lrr}
\hline \hline Parameter & Estimate & Standard Error \\
\hline$\beta$ & 0.9947 & 0.0013 \\
$\theta_{d}$ & 0.0015 & 0.0006 \\
$\theta_{p}$ & 0.0465 & 0.0036 \\
$\lambda_{O 0}$ & 0.0060 & 0.0039 \\
$\lambda_{O 1}$ & 0.0015 & 0.0005 \\
$\lambda_{L 0}$ & -0.0051 & 0.0010 \\
$\lambda_{L 1}$ & 0.0629 & 0.0007 \\
$\pi$ & 0.2613 & 0.0127 \\
$\phi$ & 0.9750 & 0.0017 \\
$\rho$ & 0.0476 & 0.0132 \\
$\mu_{C}$ & 7.3935 & 0.0288 \\
$\sigma_{C}^{2}$ & 0.7827 & 0.0087 \\
$\mu_{\alpha}$ & -0.7603 & 0.0184 \\
$\sigma_{\alpha}^{2}$ & 2.5271 & 0.0213 \\
$\mu_{V}$ & 13.0424 & 0.0247 \\
$\sigma_{V}^{2}$ & 0.9500 & 0.0083 \\
$\psi_{0 T}$ & 1.9821 & 0.0265 \\
$\psi_{1 T}$ & 0.0886 & 0.0031 \\
$\psi_{0 \bar{T}}$ & 20.6203 & 0.0441 \\
$\psi_{1 \bar{T}}$ & 0.8160 & 0.0017 \\
Log-likelihood & & -29343.19 \\
\hline
\end{tabular}

Table 3: Maximum Likelihood Estimates

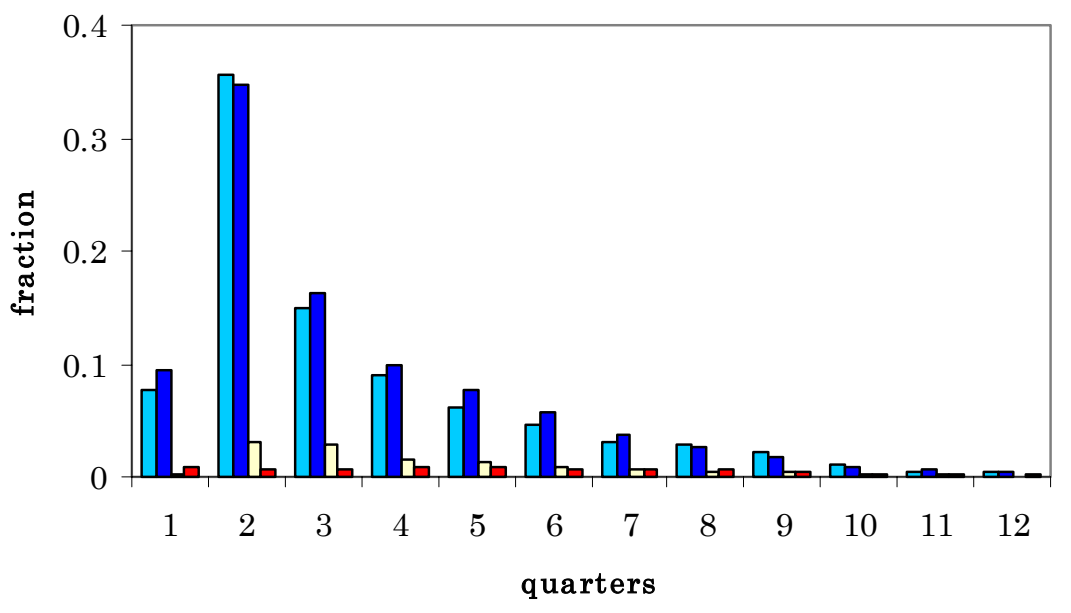

$\square$ data (filing) $\square$ data (settlement)

qfit (filing) $\square$ fit (settlement)

Figure 6: Histogram of Timing for Settlement and Filing 


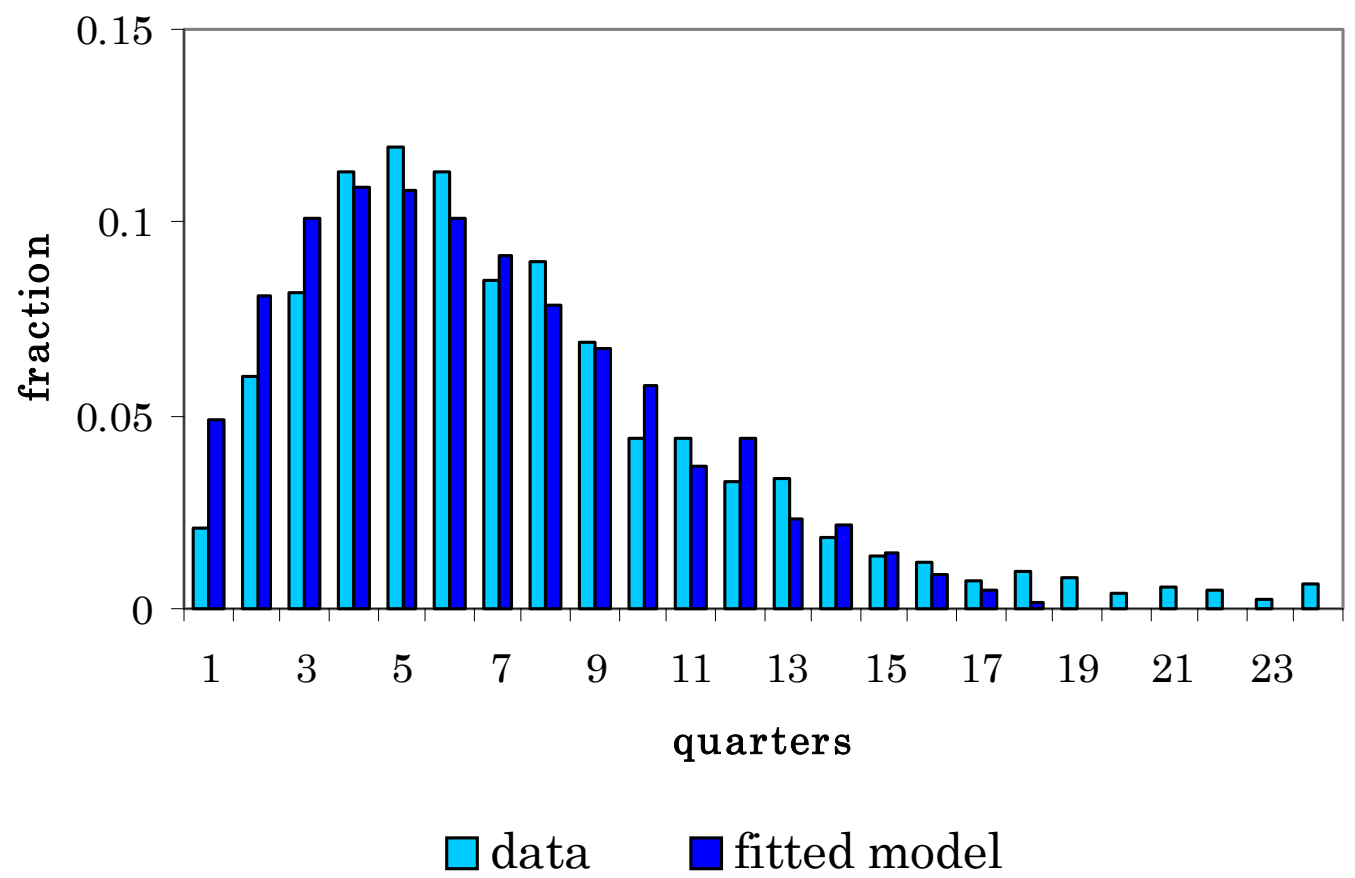

Figure 7: Histogram of Time to Settlement after Filing

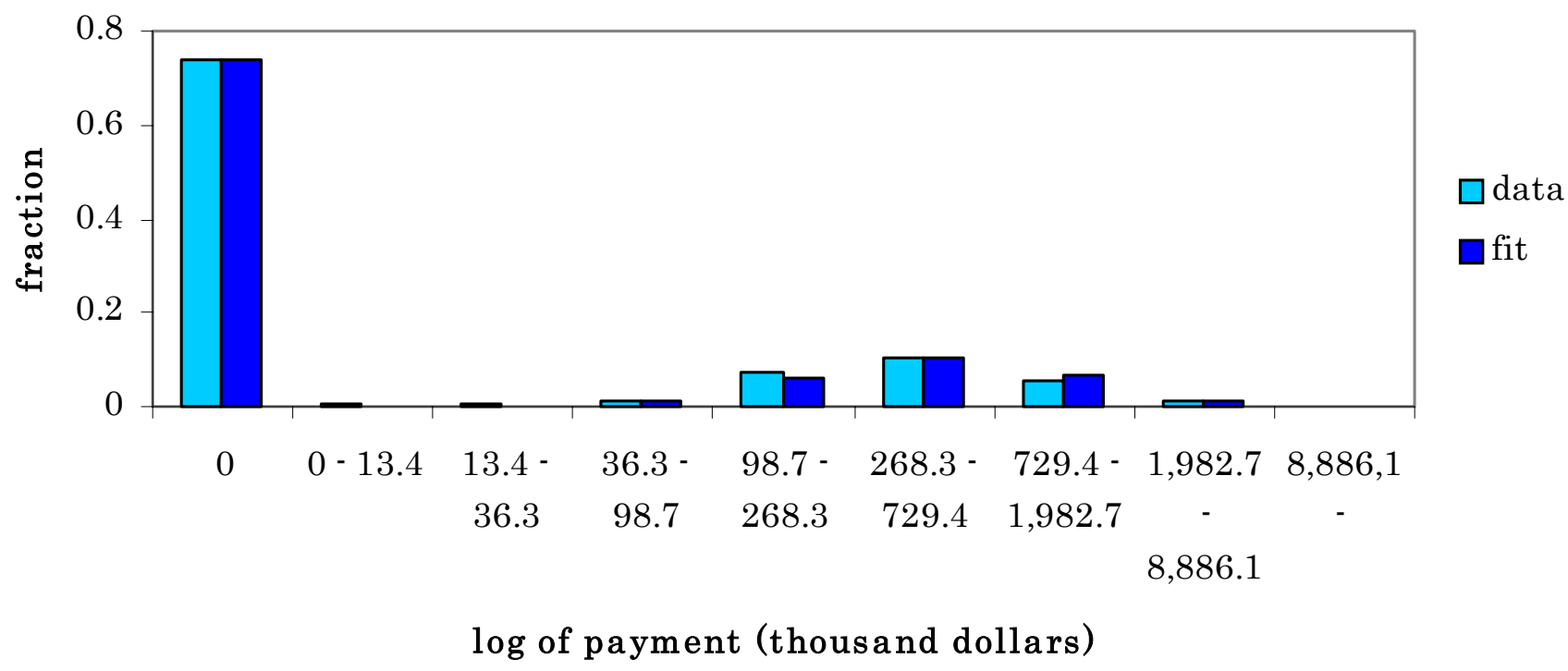

Figure 8: Histogram of Payments for Cases Resovled by Court Judgment 


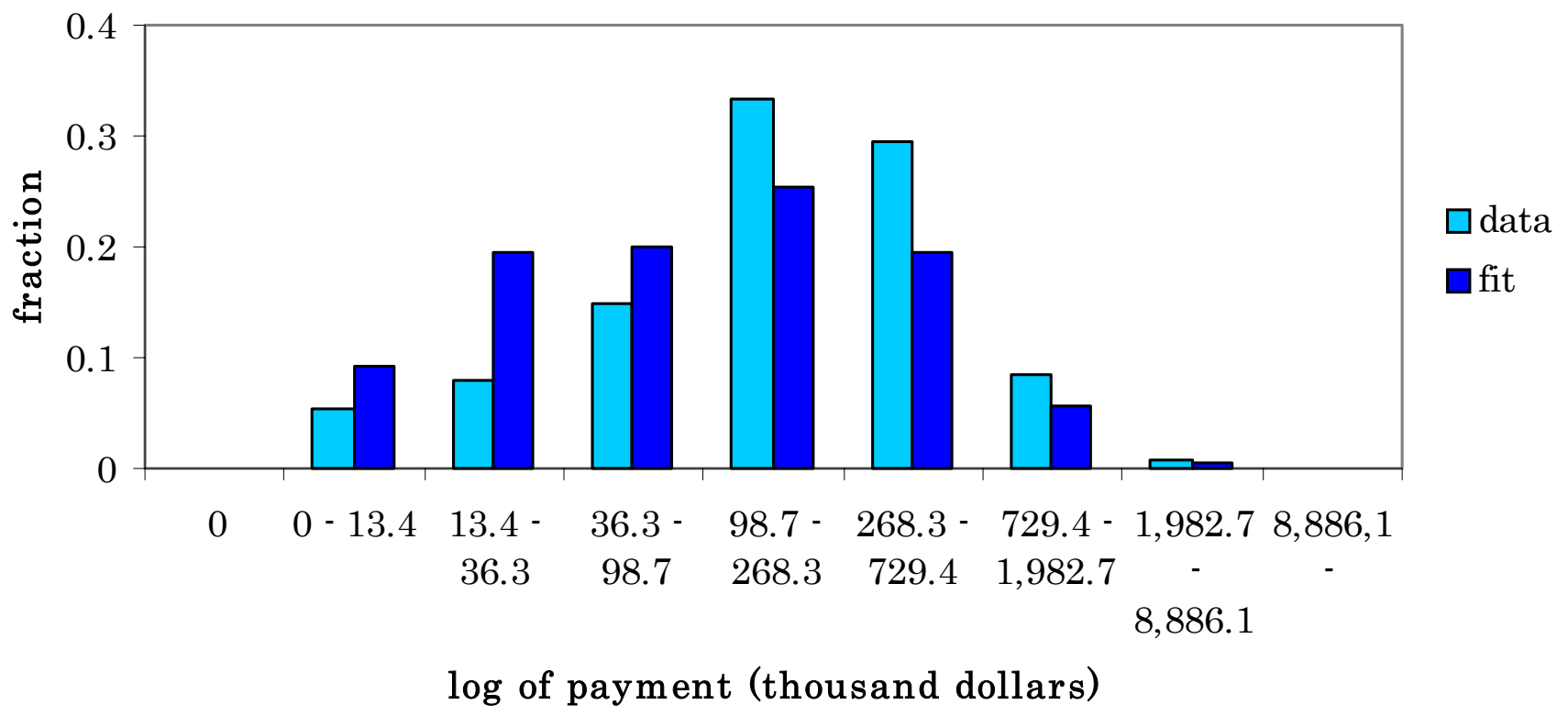

Figure 9: Histogram of Payments for Cases Settled after Filing

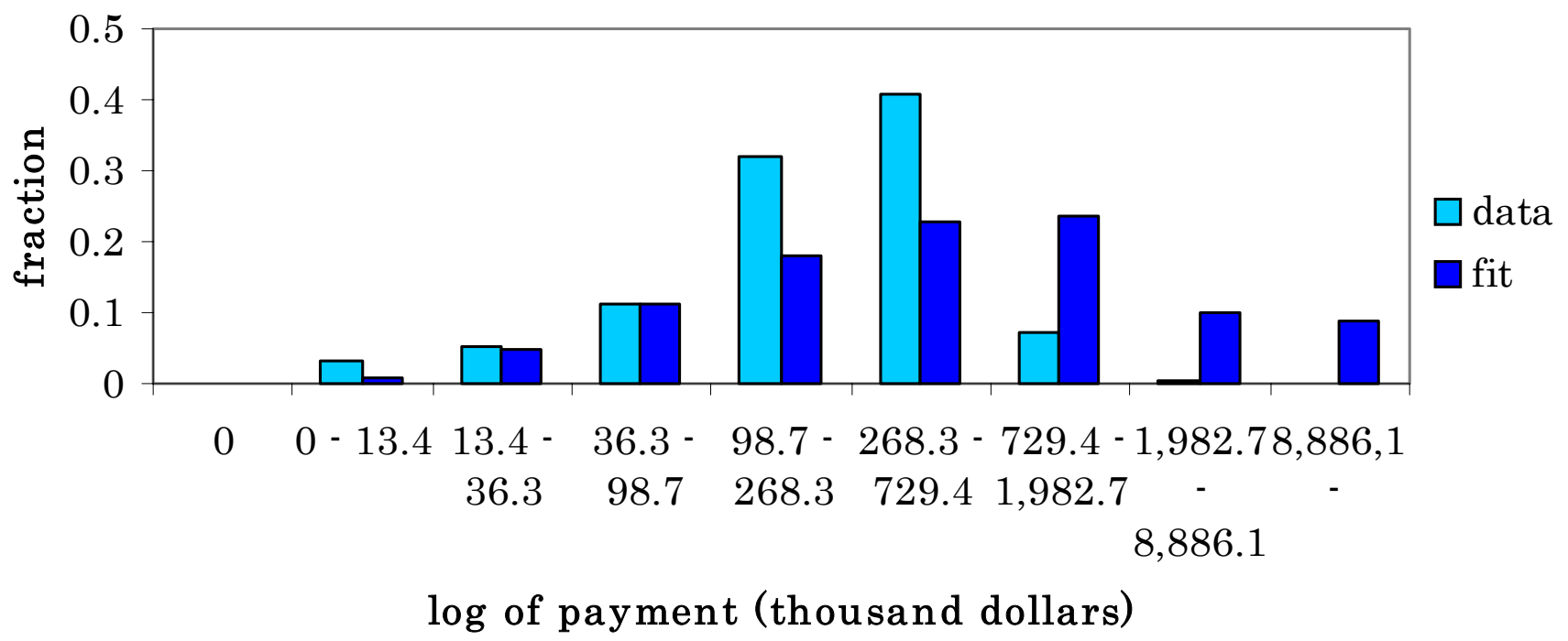

Figure 10: Histogram of Payment for Cases Settled without Filing 
bins are precise though the fit for the rest of the bins have a gap of 0.05 to 0.1 . Figure 10 presents the fit of the model regarding the compensation payment for the cases settled before filing. Similar to Figure 9, the shape is captured generally well, though fit for several bins are not very good. From Figures 9 and 10, the model overpredicts low compensation payment in the litigation phase, while the model overpredicts the high compensation payment for cases settled in the pre-litigation phase.

\section{Tort Reform Experiments}

A commonly held opinion is that medical malpractice litigation has contributed to rising health care costs both directly, through high litigation costs, and indirectly, through "defensive medicine" aimed at preventing litigation (see e.g., U.S. Congress Joint Economic Committee, 2003). The direct cost of medical malpractice litigation was about $\$ 24$ billion in 2002 and has doubled in the past 12 years (Tillinghast Towers-Perrin, 2003) The indirect cost through "defensive medicine" is estimated to be in the order of $\$ 60$ billion per year (Pinkerton 1999).

Rising medical malpractice insurance premia due to excessive litigation costs have led to what many believe to be a state of crisis. According to the American Medical Association, 20 states are in a "full-blown medical liability crisis" in which doctors "retire early, relocate or give up performing high-risk medical procedures." 15 In response to these problems, medical liability reforms, such as caps on jury awards or restrictions on lawyer fees, were adopted in many states during the 1990s and are currently been considered at the federal level.

In this section, I use the estimated model to conduct counterfactual policy experiments on proposed reforms of the medical liability system. Specifically, I consider three proposed policies: (1) cap of $\$ 250,000$ on jury award, (2) elimination of the contingency fee rule, and (3) loser-pay-all legal cost allocation. These policies affect the time to resolution and associated legal costs in a way that has important policy implications. Shorter legal procedures would save legal costs for the parties and would benefit society by reducing congestion in the legal system. Savings of legal costs would also lower the deadweight loss of litigation because legal fee is simply a transaction cost to both parties (See, e.g. the classical work of Calabresi (1970)). Also, the doctors would have less incentive to practice defensive medicine if medical malpractice litigations becomes less costly. It is therefore important to try to evaluate the effect of these proposed policies. My approach offers a systematic way of addressing these quantitative issues in the context of an equilibrium framework.

\footnotetext{
${ }^{15}$ See the Advocacy section of American Medical Association's webpage at http://www.ama-assn.org/
} 


\subsection{Caps on Jury Award}

The first policy experiment I conduct is a policy to cap the jury award at $\$ 250,000 .{ }^{16}$ This policy obviously does not affect cases whose jury award is less than $\$ 250,000$ without the cap. Hence, in conducting the policy experiment, I use $V^{\prime}=\min \{V, 250000\}$ as the (unobserved) realization of the jury award instead of using the (unobserved) realization of $V$ from $F_{V}(\cdot)$. As discussed in the model section, decrease in $V$ enhances early settlement.

\begin{tabular}{lccc}
\hline \hline & $\begin{array}{c}\text { Expected Time } \\
\text { to Resolution } \\
\text { (quarters) }\end{array}$ & $\begin{array}{c}\text { Expected } \\
\text { Cost }\end{array}$ & $\begin{array}{c}\text { Expected } \\
\text { Payment }\end{array}$ \\
& (dollars) & (dollars) \\
Baseline model & 9.65 & 45,959 & 354,910 \\
Policy Experiment 1 & 8.25 & 32,489 & 242,343 \\
\hline
\end{tabular}

Table 4: Policy Experiment 1: Cap on Jury Award

The results of the experiment are presented in Table 4. The mean time to resolution is decreased by $14.5 \%$ from 9.65 quarters to 8.25 quarters. The decrease mostly comes from the cases settled after filing lawsuit, as observed in Figure 11. The decision in the pre-litigation phase are not substantially affected. The reduction in mean legal cost is $28.7 \%$ (from $\$ 45,959$ to $\$ 32,489$ ). The reduction of the cost is larger than that of the mean duration, because the reduction of duration is mostly in the litigation phase, which is associated with a higher per-period legal cost than in the pre-litigation phase. The mean payment also decreases by $31.7 \%$ (from $\$ 354,910$ to $\$ 242,343$ ). This immediately follows from the capping of awards.

\subsection{Eliminating Contingency Fee Rule}

The second policy experiment I conduct is elimination of the contingency fee rule. The contingency fee arrangement, which is employed for vast majority of the cases on injuries, makes the plaintiff's lawyers entitled to a fraction (typically one-third to 40\%) of the money received from the defendant only if a positive payment is received. The contingency fee rule allows the plaintiff to continue the

\footnotetext{
${ }^{16}$ Capping of the jury award is typically on non-economic damages, which include compensation for pain and suffering and punitive damages whose objective is to provide punishment for the malicious or wanton misconduct of the defendant. For example, the HEALTH Act of 2004 currently in the Congress considers a cap of $\$ 250,000$ for non-economic damages and twice the amount of economic damages awarded or $\$ 250,000$, whichever is greater, as a cap for punitive damage.
} 


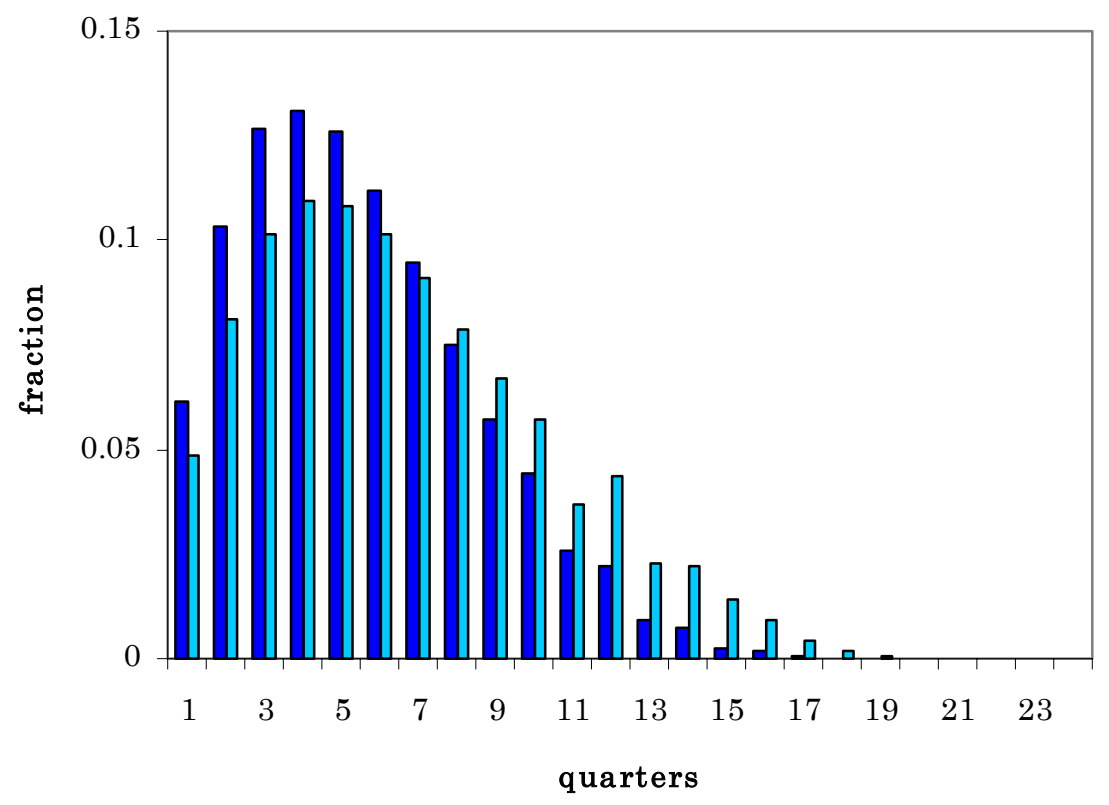

$\square$ experiment $1 \quad \square$ baseline model

Figure 11: Histogram of Time to Settlement after Filing

case with no direct legal costs per period. Hence, the elimination of the contingency fee, which makes the legal cost of the plaintiff to be accrued as the case prolongs, is likely to result in earlier settlements. In conducting the policy experiment, I assumed that the plaintiff pays per-period legal costs $C_{p O}$ and $C_{p L}$ in the pre-litigation and litigation phases, respectively. $C_{p O}$ and $C_{p L}$ are drawn from the same distribution that the defendant's per-period legal costs is drawn. Considering that the legal industry is competitive, it is natural to assume that the cost is drawn from the same distribution both for the plaintiff and the defendant.

The results of the experiment are presented in Table 5 . The mean time to resolution is decreased by $30.7 \%$ (from 9.65 quarters to 6.68 quarters). More than $45 \%$ of the cases file immediately and settle earlier after filing now that the plaintiff directly incurs per-period legal cost. The reduction in mean legal cost is $16.2 \%$ from $\$ 45,959$ to $\$ 38,184$. The mean payment also decreases, from $\$ 354,910$ to $\$ 108,884$. The decrease in mean payment is due to a large fraction of cases settled with zero payment, which did not occur in the baseline model (see Figure 12).

\subsection{Loser-pay-all Legal Fee Allocation}

The third policy experiment I conduct is the implementation of a loser-pay-all allocation of legal fees. In the United States, parties typically pay the legal cost of their lawyers regardless of the 


\begin{tabular}{lccc}
\hline \hline & $\begin{array}{c}\text { Expected Time } \\
\text { to Resolution } \\
\text { (quarters) }\end{array}$ & $\begin{array}{c}\text { Expected } \\
\text { Cost }\end{array}$ & $\begin{array}{c}\text { Expected } \\
\text { Payment }\end{array}$ \\
& & (dollars) & (dollars) \\
Baseline model & 9.65 & 45,959 & 354,910 \\
Policy Experiment 2 & 6.68 & 38,184 & 108,884 \\
\hline
\end{tabular}

Table 5: Policy Experiment 2: Elimination of Contingency Fee Rule

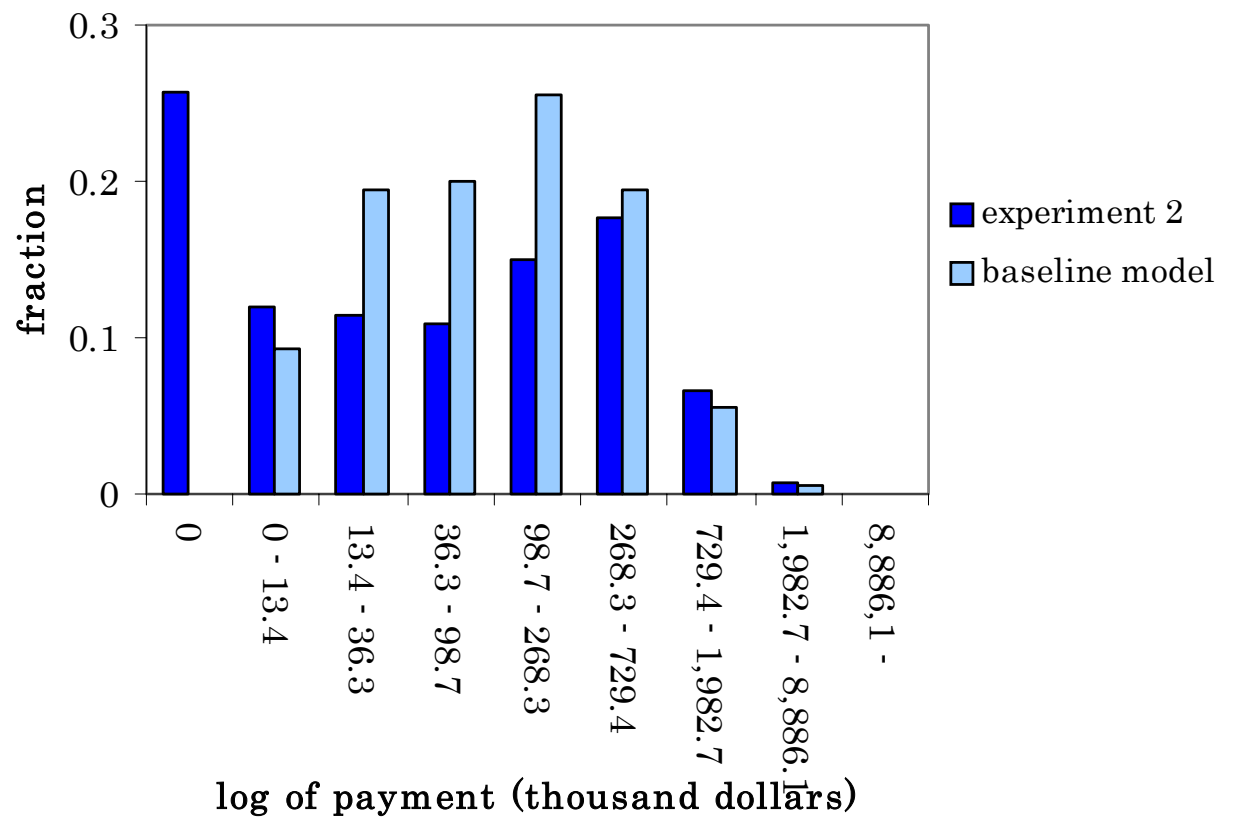

Figure 12: Histogram of Payment for Cases Settled after Filing 
outcome of the judgment (known as the "American rule") The loser-pay-all legal fee allocation (known as the "English rule"), in contrast, prescribes that the losing party also pays the legal costs of the party prevailing at trial.

\begin{tabular}{lccc}
\hline \hline & $\begin{array}{c}\text { Expected Time } \\
\text { to Resolution } \\
\text { (quarters) }\end{array}$ & $\begin{array}{c}\text { Expected } \\
\text { Cost }\end{array}$ & $\begin{array}{c}\text { Expected } \\
\text { Payment }\end{array}$ \\
& (dollars) & (dollars) \\
\hline Baseline model & 9.65 & 45,959 & 354,910 \\
Policy Experiment 1 & 10.63 & 112,114 & 106,360 \\
\hline
\end{tabular}

Table 6: Policy Experiment 3: Loser-pay-all Legal Fee Allocation

In this policy experiment, like in the previous one, I assume the legal cost on the plaintiff's side, which is incurred by the plaintiff's lawyer under the contingency fee rule, is drawn from the same distribution as the legal costs on the defendant's side. Since the legal cost that matters here is the cost after filing a lawsuit, the cost to be shifted if the defendant wins is $T \cdot C_{L}$. Denoting the realization of per-period cost for the plaintiff as $C_{P}$, the legal cost to be shifted if the plaintiff win is $T \cdot C_{P}$. The outcome of the court case is now $\left\{V,-V-T \cdot C_{P}\right\}$ with probability $\pi$ and $\left\{-T \cdot C_{L}, 0\right\}$ with probability $1-\pi$. Hence, the difference in payoffs between prevailing and losing the verdict is larger under the English rule.

The results of the experiment are presented in Table 6. The mean time to resolution increases by $10.1 \%$ (from 9.65 quarters to 10.63 quarters). Increased difference in possible court outcomes prevents parties to settle early. The mean total cost increases from $\$ 45,959$ to $\$ 112,114$. The mean payment decreases from $\$ 354,910$ to $\$ 106,360$.

\subsection{Policy Implications}

Effects of tort reform on medical malpractice litigations affect the welfare of the society in various ways. The effects of the reforms are on the congestion of the judicial system, on the savings of legal cost for the society, and on the behavior of the doctors. Regarding the effects on the congestion of the judicial system, reforms that would shorten the time to resolution of a dispute is desired in order to decrease the court's case load. The savings of legal cost improves the welfare of the both party in disputes, hence reduces the deadweight loss of litigation. On the effects on the behavior of the doctors, less costly litigation decreases the incentive to practice defensive medicine, which helps 


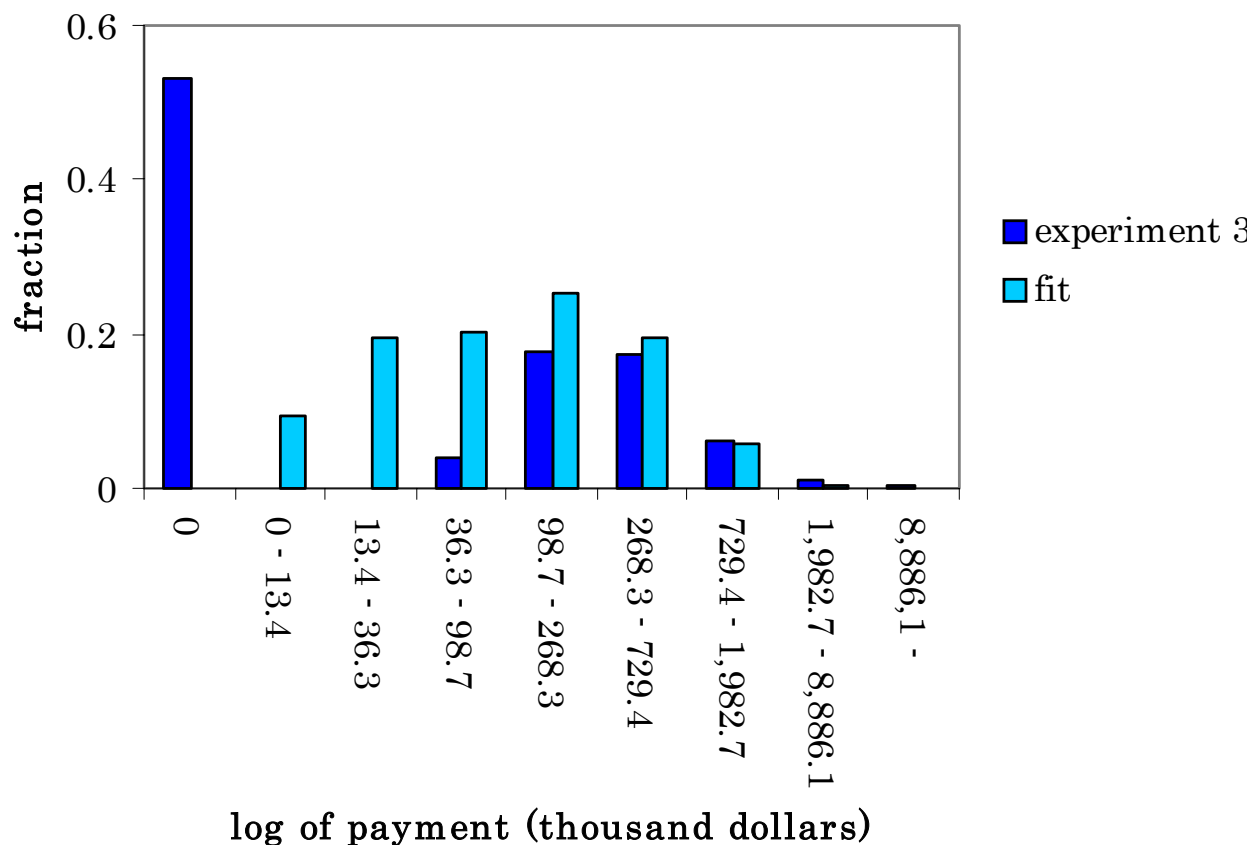

Figure 13: Histogram of Payments for Cases Settled after Filing

to avoid medically unnecessary precautionary measures, such as excessive medical examinations.

I find that capping jury awards or eliminating the contingency fee rule significantly shortens the expected time to resolution and lowers the expected total legal costs. Hence, I conclude that these reforms could have important welfare implications. On the other hand, replacing the current system with the "loser-pay-all" allocation of legal fees would delay resolution and increase costs, hence is not a desirable policy.

\section{Concluding Remarks}

This paper studies the dispute resolution process with special emphasis on the dynamic pattern of litigation and settlement as well as the associated payments and legal costs. I propose a dynamic bargaining model of dispute resolution with learning, estimate the model using micro data on medical malpractice disputes, and use the estimated model to assess the impact of proposed tort reforms. I found that the model fits all the aspect of the data well and learning plays a quantitatively important role in explaining the dynamic patterns of litigation and settlement observed in the data. Using the estimated model, I conduct policy experiments on some of the proposed tort reforms. I find that capping jury awards or eliminating the contingency fee rule significantly shortens the 
expected time to resolution and lowers the expected total legal costs. On the other hand, "loserpay-all" allocation of legal fees would delay resolution and increase costs.

\section{Appendix}

\subsection{Appendix A}

Proof (Proposition 1). Denote the belief of the plaintiff by $b^{p}$ and that of the defendant by $b^{d}$. Note that I have no need to consider beliefs to follow a distribution because no learning is taking place. The continuation values at the last stage in the litigation phase are written as

$$
\begin{aligned}
V_{T}^{p} & =\phi \beta \max \left\{b^{d} V+C_{L}, b^{p} V\right\}+(1-\phi) \beta b^{p} V \\
V_{T}^{d} & =-\phi \beta b^{d} V-C_{L}+(1-\phi) \beta \max \left\{-b^{p} V,-b^{d}-C_{L}\right\} .
\end{aligned}
$$

Note that I no longer have expectation operators or the state variable $k_{t}$ because no information arrives and the idiosyncratic shock of arrival of information no longer exists. Following the same argument as in the main text, the players do not settle iff

$$
b^{p}-b^{d}>\frac{C_{L}}{V}
$$

Suppose that players do not settle at the last stage. In this case the continuation values at the last stage $\left(t_{L}+T\right)$ are written as $V_{T}^{p}=\beta b^{p} V$ and $V_{T}^{d}=-\beta\left[b^{d} V-C_{L}\right]$. Hence, the continuation value at $t=t_{L}+T-1$ if players do not settle at $t=t_{L}+T$ is

$$
\begin{aligned}
& V_{T-1}^{p}=\phi \beta \max \left\{-V_{T}^{d}+C_{L}, V_{T}^{p}\right\}+(1-\phi) \beta V_{T}^{p}, \\
& V_{T-1}^{d}=\phi \beta\left\{V_{T}^{d}-C_{L}\right\}+(1-\phi) \beta \max \left\{-V_{T}^{p}, V_{T}^{d}-C_{L}\right\} .
\end{aligned}
$$

Players do not settle iff

$$
\begin{aligned}
C_{L} & <V_{T}^{p}+V_{T}^{d} \\
& =\beta\left[b^{p}-b^{d}\right] V-\beta C_{L} \\
b^{p}-b^{d} & >\frac{(1+\beta) C_{L}}{\beta V}
\end{aligned}
$$

Hence, if players do not settle at $t=t_{L}+T-1$, they also do not settle at $t=t_{L}+T$ since

$$
b^{p}-b^{d}>\frac{(1+\beta) C_{L}}{\beta V}>\frac{C_{L}}{V} .
$$


Following the same reasoning, players settle at $t>t_{L}$ iff

$$
b^{p}-b^{d} \leq \frac{\left(1+\beta^{T-t+1}\right) C_{L}}{(1-\beta) \beta^{T-t} V} .
$$

Given that players settle at the subgame starting at $t>t_{L}$, they always settle in any subgame starting at $t^{\prime}<t$. This is because settlement at $t$ makes $V_{t}^{p}+V_{t}^{d}=0<C_{L}$, which makes the players settle at $t-1$, which makes the player settle at $t-2$, and so on. Therefore, in the litigation stage game, the players either settle immediately (if $b^{p}-b^{d}>\frac{\left(1+\beta^{T+1}\right) C_{L}}{(1-\beta) \beta^{T} V}$ ) or never settle and face judgment (if $\left.b^{p}-b^{d} \leq \frac{\left(1+\beta^{T+1}\right) C_{L}}{(1-\beta) \beta^{T} V}\right)$.

Now, I consider the pre-litigation phase. I can follow the same reasoning as above to show that if players disagree in the first period, they never agree in the subsequent subgame. In such a case, the plaintiff prefers to file a lawsuit immediately because delaying results in more discounting on the expected award. Hence, the plaintiff files immediately and the case does not spend any time in the pre-litigation phase. Therefore, the players disagree in the first stage, as well as in any stage of the game, if (by multiplying both sides by $\beta^{T} V$ )

$$
\left(b^{p}-b^{d}\right) \beta^{T} V>\frac{\left(1+\beta^{T+1}\right) C_{L}}{(1-\beta)},
$$

while a case is settled immediately if

$$
\left(b^{p}-b^{d}\right) \beta^{T} V \leq \frac{\left(1+\beta^{T+1}\right) C_{L}}{(1-\beta)} .
$$

This proves that a case is either settled immediately or judged by the court.

\subsection{Appendix B}

Pre-litigation stage cost $C_{O}$ and litigation stage cost $C_{L}$ are

$$
\begin{aligned}
C_{O} & \sim \operatorname{LogNormal}\left(\mu_{C}, \sigma_{C}^{2}\right) \\
C_{L} & =(1+\alpha) C_{O} \text { and } \alpha \sim \operatorname{LogNormal}\left(\mu_{\alpha}, \sigma_{\alpha}^{2}\right) .
\end{aligned}
$$

where

$$
C=\left\{\begin{array}{cl}
t_{S} C_{O} & \text { if } l=\text { NOFILE } \\
t_{L} C_{O}+\left(t_{S}-t_{L}\right)(1+\alpha) C_{O} & \text { if } l=\text { FILE }
\end{array}\right.
$$

Estimating $\left(\mu_{C}, \sigma_{C}^{2}\right)$ I can identify $\left(\mu_{C}, \sigma_{C}^{2}\right)$ from the cases settled without litigation $(l=$ NOFILE). I can directly observe the realization of the per period cost given data on total cost 
and settlement duration, since

$$
C_{O}=\frac{C}{t_{S}}
$$

This expression implies that I can obtain the estimates for mean and variance of $C_{O}$ as follows:(variable $x$ for observation $i$ is expressed as $x_{i}$, where $i=1, \ldots, N_{O}$ )

$$
\begin{aligned}
\widehat{E\left[C_{O}\right]} & =\frac{1}{N_{O}} \sum_{i=1}^{N_{O}} \frac{C_{i}}{t_{s i}} \\
\widehat{\operatorname{Var}\left[C_{O}\right]} & =\frac{1}{N_{O}} \sum_{i=1}^{N_{O}}\left(\frac{C_{i}}{t_{s i}}-\sum_{i} \frac{C_{i}}{t_{s i}}\right)^{2} .
\end{aligned}
$$

Thus, I can find estimates for $\left(\mu_{C}, \sigma_{C}^{2}\right)$ by solving the system of equations

$$
\begin{aligned}
E\left[C_{O}\right] & =\exp \left[\mu_{C}+\frac{\sigma_{C}^{2}}{2}\right], \\
\operatorname{Var}\left(C_{O}\right) & =\exp \left[2 \mu_{C}+\sigma_{C}^{2}\right]\left[\exp \left(\sigma_{C}^{2}\right)-1\right],
\end{aligned}
$$

which gives

$$
\begin{aligned}
& \widehat{\mu}_{C}=\ln \frac{1}{N_{O}} \sum_{i=1}^{N_{O}} \frac{C_{i}}{t_{s i}}-\frac{1}{2} \ln \left[\frac{\frac{1}{N_{O}} \sum_{i=1}^{N_{O}}\left(\frac{C_{i}}{t_{s i}}-\frac{1}{N_{O}} \sum_{i=1}^{N_{O}} \frac{C_{i}}{t_{s i}}\right)^{2}}{\exp \left(\frac{2}{N_{O}} \sum_{i=1}^{N_{O}} \frac{C_{i}}{t_{s i}}\right)}+1\right], \\
& \widehat{\sigma}_{C}^{2}=\ln \left[\frac{\frac{1}{N_{O}} \sum_{i=1}^{N_{O}}\left(\frac{C_{i}}{t_{s i}}-\frac{1}{N_{O}} \sum_{i=1}^{N_{O}} \frac{C_{i}}{t_{s i}}\right)^{2}}{\exp \left(\frac{2}{N_{O}} \sum_{i=1}^{N_{O}} \frac{C_{i}}{t_{s i}}\right)}+1\right] .
\end{aligned}
$$

Estimating $\left(\mu_{\alpha}, \sigma_{\alpha}^{2}\right)$ The total cost $C$ for the cases with litigation $(l=F I L E)$ can be written as

$$
\begin{aligned}
C & =t_{O} C_{O}+t_{L} C_{L} \\
& =t_{O} C_{O}+t_{L}(1+\alpha) C_{O} \\
& =\left(t_{O}+t_{L}\right) C_{O}+t_{L} \alpha C_{O} .
\end{aligned}
$$


Because independent random variables $\alpha$ and $C_{O}$ both follows log-normal distribution, I can show that $E\left[\alpha C_{O}\right]=E[\alpha] E\left[C_{O}\right]^{17}$ Therefore, I have

$$
\begin{aligned}
E[C] & =\left(t_{O}+t_{L}\right) E\left[C_{O}\right]+t_{L} E\left[\alpha C_{O}\right] \\
& =\left(t_{O}+t_{L}\right) E\left[C_{O}\right]+t_{L} E[\alpha] E\left[C_{O}\right],
\end{aligned}
$$

which implies

$$
E[\alpha]=\frac{E[C]}{t_{L} E\left[C_{O}\right]}-\left(1+\frac{t_{O}}{t_{L}}\right) .
$$

Now that I have estimates for $\left(\mu_{C}, \sigma_{C}^{2}\right)$, I can identify the mean of $\alpha$ using mean of total cost $C$ and mean of $C_{O}$ as above, and can compute it as follows: (variable $x$ for observation $i$ is expressed as $x_{i}$, where $i=1, \ldots, N_{L}$ )

$$
\widehat{E[\alpha]}=\frac{1}{N_{L}} \sum_{i=1}^{N_{L}}\left[\frac{C_{i}}{t_{L i} \widehat{E\left[C_{O}\right]}}-\left(1+\frac{t_{O i}}{t_{L i}}\right)\right]
$$

where $\widehat{E\left[C_{O}\right]}=\frac{1}{N_{O}} \sum_{i=1}^{N_{O}} \frac{C_{i}}{t_{s i}}$ is obtained in the previous stage. Now, the variance of the total cost $C$ can be written as

$$
\operatorname{Var}[C]=\left(t_{O}+t_{L}\right)^{2} \operatorname{Var}\left[C_{O}\right]+t_{L}^{2} \operatorname{Var}\left[\alpha C_{O}\right]+2\left(t_{O}+t_{L}\right) t_{L} \operatorname{Cov}\left[C_{O}, \alpha C_{O}\right],
$$

where

$$
\begin{aligned}
\operatorname{Cov}\left[C_{O}, \alpha C_{O}\right] & =E\left[\left(C_{O}-E\left[C_{O}\right]\right)\left(\alpha C_{O}-E\left[\alpha C_{O}\right]\right)\right] \\
& =E\left[\alpha C_{O}^{2}\right]-E\left[C_{O}\right] E\left[\alpha C_{O}\right] .
\end{aligned}
$$

Since $\alpha$ and $C_{O}$ follow lognormal distributions, the random variables $\alpha C_{O}$ and $\alpha C_{O}^{2}$ also follow lognormal distributions. This is because product of independent random variables following lognormal distribution follows lognormal distribution as sum of independent random variables following normal distribution follows normal distribution. Thus, I have

$$
\begin{aligned}
E\left[\alpha C_{O}\right] & =\exp \left[\mu_{C}+\mu_{\alpha}+\frac{\sigma_{C}^{2}+\sigma_{\alpha}^{2}}{2}\right], \\
E\left[\alpha C_{O}^{2}\right] & =\exp \left[\mu_{C}+2 \mu_{\alpha}+\frac{\sigma_{C}^{2}+2 \sigma_{\alpha}^{2}}{2}\right], \\
\operatorname{Var}\left[\alpha C_{O}\right] & =\left[\exp \left(\sigma_{C}^{2}+\sigma_{\alpha}^{2}\right)-1\right] \exp \left[2 \mu_{C}+2 \mu_{\alpha}+\sigma_{C}^{2}+\sigma_{\alpha}^{2}\right] .
\end{aligned}
$$

\footnotetext{
${ }^{17}$ This is because mean of sum of two independent variables following normal distribution is sum of means.
} 
The variance of $C$ can now be rewritten as

$$
\begin{aligned}
\operatorname{Var}[C]= & \left(t_{O}+t_{L}\right)^{2} \operatorname{Var}\left[C_{O}\right]+t_{L}^{2} \operatorname{Var}\left[\alpha C_{O}\right]+2\left(t_{O}+t_{L}\right) t_{L} \operatorname{Cov}\left[C_{O}, \alpha C_{O}\right] \\
= & \left(t_{O}+t_{L}\right)^{2} \exp \left[2 \mu_{C}+\sigma_{C}^{2}\right]\left[\exp \left(\sigma_{C}^{2}\right)-1\right] \\
& +t_{L}^{2}\left[\exp \left(\sigma_{C}^{2}+\sigma_{\alpha}^{2}\right)-1\right] \exp \left[2 \mu_{C}+2 \mu_{\alpha}+\sigma_{C}^{2}+\sigma_{\alpha}^{2}\right] \\
& +2\left(t_{O}+t_{L}\right) t_{L}\left[\exp \left(\mu_{C}+2 \mu_{\alpha}+\frac{\sigma_{C}^{2}+2 \sigma_{\alpha}^{2}}{2}\right)-\exp \left(2 \mu_{C}+\mu_{\alpha}+\frac{2 \sigma_{C}^{2}+\sigma_{\alpha}^{2}}{2}\right)\right] .
\end{aligned}
$$

Hence, I can find $\widehat{\mu_{\alpha}}$ and $\widehat{\sigma_{\alpha}^{2}}$ by solving the following with $\widehat{\mu_{C}}$ and $\widehat{\sigma_{C}^{2}}$ obtained above.

$$
\begin{aligned}
& \widehat{\mu_{\alpha}}+\frac{\widehat{\sigma_{\alpha}^{2}}}{2}=\frac{1}{N_{L}} \sum_{i=1}^{N_{L}}\left[\frac{C_{i}}{t_{L i} \widehat{E\left[C_{O}\right]}}-\left(1+\frac{t_{O i}}{t_{L i}}\right)\right],
\end{aligned}
$$

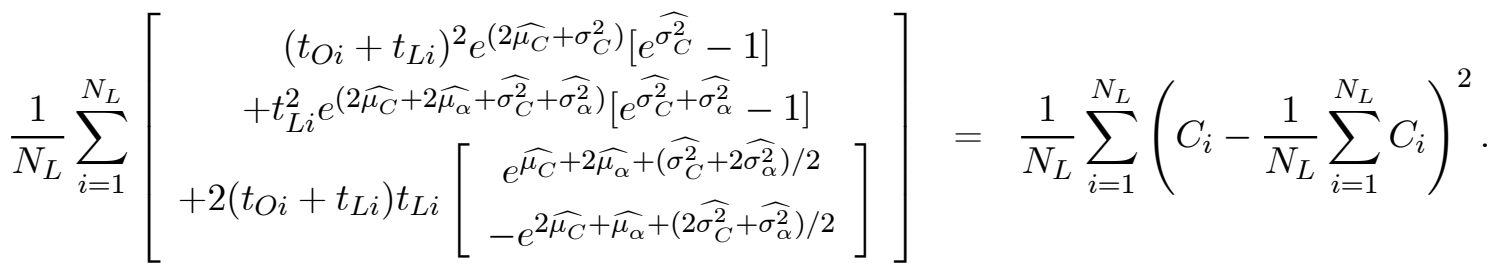

That is,

$$
\begin{aligned}
& \widehat{\mu_{\alpha}}=\ln \left(\frac{1}{N_{L}} \sum_{i=1}^{N_{L}}\left[\frac{C_{i}}{t_{L i} \widehat{E\left[C_{O}\right]}}-\left(1+\frac{t_{O i}}{t_{L i}}\right)\right]\right)-\frac{1}{2} \widehat{\sigma_{\alpha}^{2}}, \\
& \widehat{\sigma_{\alpha}^{2}}=-\widehat{\sigma_{C}^{2}}+\ln \left[1+\frac{1}{N_{L}} \sum_{i=1}^{N_{L}} \frac{\left\{\begin{array}{c}
\left(C_{i}-\frac{1}{N_{L}} \sum_{i=1}^{N_{L}} C_{i}\right)^{2}-\left(t_{O i}+t_{L i}\right)^{2} \operatorname{Var(C}(\widehat{C}) \\
-2\left(t_{O i}+t_{L i}\right) t_{L i}\left[e^{\widehat{E[C]}+2 \widehat{E[\alpha]}}-e^{2 \widehat{E[C]}+\widehat{E[\alpha]}]}\right.
\end{array}\right\}}{t_{L i}^{2} \exp (2(\widehat{E[C]}+\widehat{E[\alpha]}))}\right],
\end{aligned}
$$

where expressions for $\left.\left.\widehat{E\left[C_{O}\right.}\right], \operatorname{Var(C_{O}}\right), \widehat{E[C]}, \widehat{E[\alpha]}$, and $\widehat{\sigma_{C}^{2}}$ are all computed above.

\section{References}

[1] Babcock, Linda and Greg Pogarsky, (1999) "Damage Caps and Settlement: A Behavioral Approach," Journal of Legal Studies, 28, pp. 341-370

[2] Bebchuk, Lucian A. (1984) "Litigation and settlement under imperfect information," Rand Journal of Economics, 15, pp. 404-415 
[3] Bebchuk, Lucian A. (1996) "A new theory concerning the credibility and success of threats to sue," Journal of Legal Studies, 25, pp. 1-25.

[4] Calabresi, Guido, (1970) The Costs of Accidents: Legal and Economic Analysis, Yale University Press, New Haven CT

[5] Cooter, Robert D. and Daniel L. Rubinfeld, (1989) "Economic Analysis of Legal Disputes and Their Resolution," Journal of Economic Literature, 27, pp. 1067-1097.

[6] Cooter, Robert D. and Daniel L. Rubinfeld, (1994) "An Economic Model of Legal Discovery," Journal of Legal Studies, 23, pp. 435-463

[7] Farber, Henry S. and Michelle J. White, (1991) "Medical Malpractice: An Empirical Examination of the Litigation Process," RAND Journal of Economics, 22, pp.199-217

[8] Fenn, Paul \& Neil Rickman (1999): "Delay and Settlement in Litigation," Economic Journal, 109, pp. 476-491

[9] Fournier, Gary M. and Thomas W. Zuehlke, (1996) "The timing of out-of-dourt settlements," Rand Journal of Economics, 27, pp. 310-321

[10] Hughes, James W. and Snyder, Edward A. (1995) "Litigation and Settlement under the English and American Rules: Theory and Evidence." Journal of Law and Economics, 38, pp. 225-50

[11] Kessler, Daniel P. (1996) "Institutional Causes of Delay in the Settlement of Legal Disputes," Journal of Law, Economics, and Organization, 12, pp. 432-460

[12] Kessler, Daniel P. and Daniel L. Rubinfeld (2004) "Empirical Study of the Civil Justice System," NBER Working Paper 10825

[13] Landes, W.M. (1971) "An Economic Analysis of the Courts," Journal of Law and Economics, 14, pp. 61-107

[14] Nalebuff, Barry (1987) "Credible Pretrial Negotiation," RAND Journal of Economics, 18, pp. 198-210

[15] Pinkerton, James P., (1999) "HMO's Don’t Cause Health Care's Fever," Newsday, August 12, A45

[16] Posner, R (1972) "The Behavior of Administrative Agencies," Journal of Legal Studies,1,pp. 305-347

[17] Priest, George L., and Benjamin Klein (1984) "The Selection of Disputes for Litigation," Journal of Legal Studies, 13, pp.1-56 
[18] Reinganum, Jennifer F. and Louis L. Wilde (1986) "Settlement, Litigation and the Allocation of Litigation Costs", RAND Journal of Economics, 17, pp. 557-566

[19] Sieg, Holger (2000) "Estimating a Bargaining Model with Asymmetric Information: Evidence from Medical Malpractice Disputes," Journal of Political Economy, Vol 108(5), pp. 1006-1021

[20] Snyder, Edward A. and James W. Hughes (1995) "Litigation and Settlement under the English and American Rules: Theory and Evidence," Journal of Law, Economics, and Organization, 6, pp. 345-385

[21] Spier, Kathryn E. (1992) "The Dynamics of Pretrial Negotiation," Review of Economic Studies, 59, pp. $93-108$

[22] Tillinghast Towers-Perrin, (2003) U.S. Tort Costs: 2003 Update available online at http:// www.towersperrin.com/tillinghast/publications/reports/2003_Tort_Costs_Update/Tort_Costs _Trends_2003_Update.pdf

[23] US Congress Joint Economic Committee (2003) "Liability for Medical Malpractice: Issues and Evidence." Online at http://www.house.gov/jec/tort/05-06-03.pdf

[24] Waldfogel, Joel (1995) "The Selection Hypothesis and the Relationship between Trial and Plaintiff Victory," Journal of Political Economy, 103, pp. 229-260

[25] Wittman, Donald (1989) "Dispute Resolution, Bargaining, and the Selection of Cases for Trial: A Study of the Generation of Biased and Unbiased Data," Journal of Legal Studies, 17, pp. 313-352.

[26] Yildiz, Muhamet (2003) "Bargaining Without a Common Prior - An Immediate Agreement Theorem," Econometrica, 71, pp. 793-811

[27] Yildiz, Muhamet (2004) "Waiting to Persuade," Quarterly Journal of Economics, 119, pp. 223-248

[28] Yoon, Albert, (2001) "Damage Caps and Civil Litigation: An Empirical Study of Medical Malpractice Litigation in the South," American Law 86 Economics Review, 27, pp. 199-227 